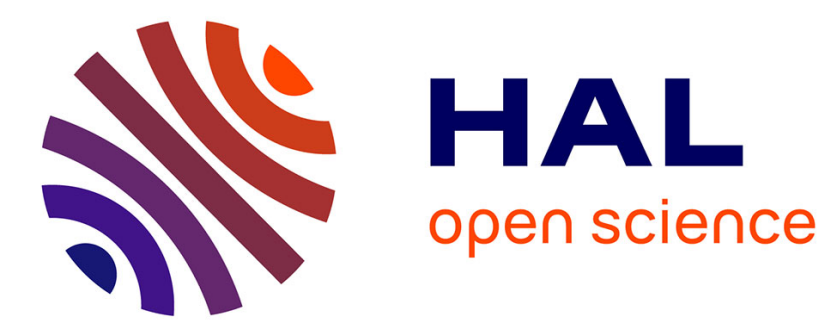

\title{
Experimental characterization and numerical modeling of micromechanical damage under different stress states
}

\author{
Mohamed Achouri, Guénaël Germain, Philippe Dal Santo, Delphine Saidane
}

\section{To cite this version:}

Mohamed Achouri, Guénaël Germain, Philippe Dal Santo, Delphine Saidane. Experimental characterization and numerical modeling of micromechanical damage under different stress states. Materials \& Design, 2013, 50, pp.207-222. 10.1016/j.matdes.2013.02.075 . hal-01057964

\section{HAL Id: hal-01057964 \\ https://hal.science/hal-01057964}

Submitted on 4 Sep 2017

HAL is a multi-disciplinary open access archive for the deposit and dissemination of scientific research documents, whether they are published or not. The documents may come from teaching and research institutions in France or abroad, or from public or private research centers.
L'archive ouverte pluridisciplinaire $\mathbf{H A L}$, est destinée au dépôt et à la diffusion de documents scientifiques de niveau recherche, publiés ou non, émanant des établissements d'enseignement et de recherche français ou étrangers, des laboratoires publics ou privés. 


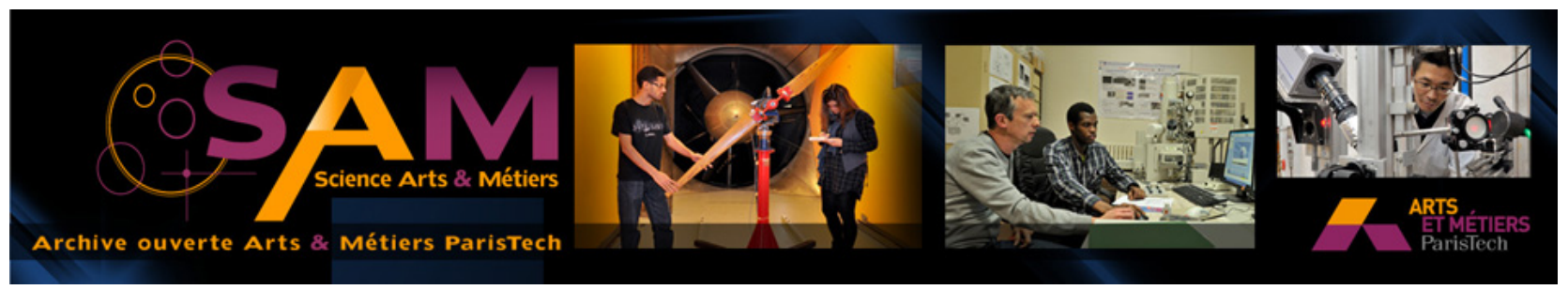

Science Arts \& Métiers (SAM)

is an open access repository that collects the work of Arts et Métiers ParisTech researchers and makes it freely available over the web where possible.

This is an author-deposited version published in: http://sam.ensam.eu

Handle ID: .http://hdl.handle.net/10985/8398

\section{To cite this version :}

Mohamed ACHOURI, Guénaël GERMAIN, Philippe DAL SANTO, Delphine SAIDANE Experimental characterization and numerical modeling of micromechanical damage under different stress states - Materials \& Design - Vol. 50, p.207-222 - 2013 


\title{
Experimental characterization and numerical modeling of micromechanical damage under different stress states
}

\author{
Mohamed Achouri ${ }^{\mathrm{a}, \mathrm{b}, *}$, Guenael Germain ${ }^{\mathrm{a}}$, Philippe Dal Santo ${ }^{\mathrm{a}}$, Delphine Saidane ${ }^{\mathrm{b}}$ \\ a LAMPA Laboratory (EA 1427), Arts et Métiers ParisTech, 2 Bd du Ronceray, 49000 Angers, France \\ ${ }^{\mathrm{b}}$ DEVILLE ASC, ZI de Beauregard, 49150 Baugé, France
}

Keywords:

Ductile fracture

Shear modified Gurson model

Parameters identification

Stress state

Punching process

Numerical simulation

\begin{abstract}
A B S T R A C T
The use of HSLA steels for the manufacture of automotive components is interesting from an engineering point of view. This family of steels, while possessing high strength, also has good formability and can be used in forming manufacturing processes. In some forming processes such as blanking, shear strain localization occurs, which causes damage and results in the final fracture of the material. This paper presents an experimental study based on in situ tests to understand and identify the physical mechanisms of ductile damage under two stress states: tension and shear. Different macroscopic tests were performed to calibrate a damage model based on a micromechanical approach. This damage model is based on the Gurson-Tvergaard-Needleman theory and presents recent improvements proposed by Nahshon and Hutchinson and by Nielsen and Tvergaard so as to better predict fracture under a wide range of stress states, especially with low levels of stress triaxiality. These extensions have made the identification of the material parameter more complicated. In this work an identification strategy has been proposed using tests on specimens with different shapes. The identified parameter values are validated and the fracture model show good predictive capability over a wide stress state range.
\end{abstract}

\section{Introduction}

Ductile fracture is a phenomenon that can be described by micromechanical analyses based on the evolution of micro-cavities using a local approach to fracture [1,2]. Alternatively, ductile fracture has also been modeled within a thermodynamics framework using the theory of continuous damage mechanics [3,4]. Modifications to the original models have since been proposed in order to improve their predictive capacity in areas such as the loss of material rigidity and the prediction of fracture. These modifications have been made by including additional effects in the constitutive formulation or in the damage evolution law, such as: the effect of the hydrostatic pressure, the temperature, viscoplasticity and the influence of crack closing [5-7].

Diverse strategies combining elasto-plastic constitutive models including rupture criteria have also been developed. Indicators of rupture have been proposed such as: the Rice and Tracey criterion [8] based on the growth of defects and the criterion proposed by Cockcroft and Latham [9] based on a void growth mechanism controlled by the principal stress. These decoupled approaches have been adopted thanks to their simple formulation and identification procedures. The development of rupture criteria based on continu-

\footnotetext{
* Corresponding author at: LAMPA Laboratory (EA 1427), Arts et Métiers ParisTech, 2 Bd du Ronceray, 49000 Angers, France.

E-mail address: mohamed.achouri@ensam.eu (M. Achouri).
}

ous damage mechanics has also been undertaken by several authors $[3,10]$. Stoughton and Yoon [11] proposed a new rupture approach based on the maximum shear stress. Their objective was to develop a fracture criterion suitable for sheet metal forming processes, which takes into account both necking and rupture.

Recently, several studies [12-21] have shown that the Lode angle, associated with the third invariant of the deviatoric stress tensor, is an essential parameter in ductile fracture. It characterizes the effect of the stress state on plastic flow and the ductile rupture of the material. Bai and Wierzbicki [21] have proposed a threedimensional fracture criterion described by the equivalent strain, the stress triaxiality and the Lode angle. This fracture surface makes it possible to differentiate between materials that are weakly or strongly dependent on the hydrostatic pressure and the Lode angle. Mirone and Corallo [23] have undertaken a local study to evaluate the influence of stress triaxiality and the Lode angle on ductile fracture, by analyzing the Tresca criterion and two models proposed by Wierzbicki. They have also shown that the relationship between the plastic deformation, the level of stress triaxiality and the Lode angle results in a fairly good prediction of ductile fracture. Gao et al. [24] have proposed a new elasto-plastic model which is a function of the hydrostatic pressure and the second and third invariants of the stress deviator. Experiments performed on specimens with a high level of triaxiality show the inter-dependence between the plastic flow mode, the level of stress triaxiality and the Lode angle. 
Despite the large volume of work devoted to understanding the phenomenon of ductile rupture and the formulation of constitutive models, their application to forming processes is complicate and can result in significant prediction errors. The first steps in using these approaches is to establish their domains of validity and to identify the model parameters under loading conditions similar to those seen in the forming process being investigated. This is crucial to ensure a realistic interpretation of the ductile fracture modes.

The focus of this work is on recently developed micromechanical ductile rupture models which include the effect of different stress states in their characterization and which deal with the damage induced via shear loads. A major limitation of models based on the Gurson [22] model is related to the fact that shear effects are not taken into account in the constitutive formulation. This therefore excludes the possibility of predicting shear localization and fracture under conditions of low stress triaxiality. Under shear dominated loading conditions, distortion of voids and the material between adjacent voids or cavities plays a crucial role in the evolution of the internal degradation of the material. In order to improve the predictive ability of the Gurson-Tvergaard-Needleman (GTN) model, under low levels of stress triaxiality, Nahshon and Hutchinson [25] and Nielsen and Tvergaard [26] have proposed further improvements to the classical GTN mode. These authors have introduced an additional term in the void evolution law to predict the accumulation of damage under a wide range of stress states, including shear loading.

The aim of this study is to identify the physical damage mechanisms under different stress states, through micro/macro experimental analyses, and to propose a strategy for the identification of optimized material parameters that cover a large range of loading conditions.

\section{Experimental study}

An experimental description of the material investigated in this work is presented below. This is based on microscopic observations performed to identify the physical damage mechanisms for two different loading conditions (tension and shear). Mechanical tests at different stress levels are also performed to study the sensitivity of the material damage to the different loading modes.

\subsection{The material}

The material investigated in this study is a High-Strength LowAlloy steel (HSLA) used to manufacture automotive safety belt anchors. The semi-finished material is received in the form of coiled metal strips with a standard thickness of $3.55 \mathrm{~mm}$. Its chemical composition is given in Table 1. Microstructural analyzes are carried out using a Scanning Electron Microscope (SEM) in the three orthogonal planes of the plate (see Fig. 1a). The microstructure shown in Fig. $1 \mathrm{~b}$ is composed of a ferritic matrix showing traces of cementite at the grain boundaries. These traces occupy about $2 \%$ of the analyzed surface and are not homogeneously distributed. The grains have an almost identical structure in all three planes.

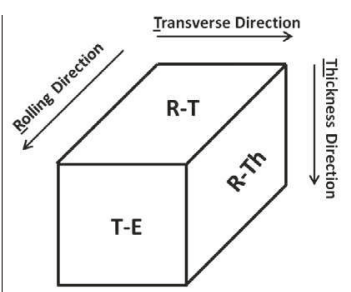

R-T: Rolling-Transverse Plan R-Th: Rolling-Thickness Plan T-Th: Transverse-Thickness Plan

(a)



(b)

Fig. 1. Microstructure of the material: (a) planes investigated in the microstructural analysis, (b) microstructure of the material for the R-Th plane.

\subsection{Microscopic analysis of inclusions}

Microscopic analyzes on three orthogonal material planes (Fig. 1a) have been performed using a Scanning Electronic Microscope (SEM). Spectrometric analysis using Energy Dispersive Spectrometry (EDS) are also done to characterize the various inclusions found in the material. The analyzed surface area on each plane is approximately $40 \mathrm{~mm}^{2}$. The aim was to determine the chemical compositions of the various inclusions.

The inclusions were classified into three main categories:

- Oxides: $\mathrm{FeO}, \mathrm{Al}_{2} \mathrm{O}_{3}$ and other "complex" inclusions, such as: $\mathrm{CaO}-\mathrm{Al}_{2} \mathrm{O}_{3}, \mathrm{MgO}-\mathrm{Al}_{2} \mathrm{O}_{3}, \mathrm{FeO}, \mathrm{CaO}$, and $\mathrm{MgO}-\mathrm{Al}_{2} \mathrm{O}_{3}-\mathrm{CaO}$.

- Sulfides: FeS-CaS.

- Oxysulfides: $\mathrm{Al}_{2} \mathrm{O}_{3}-\mathrm{CaS}$, and $\mathrm{CaO}-\mathrm{CaS}$.

Fig. 2 shows several inclusion types found in the material. Most of the inclusions observed are elongated or circular in shape. Their average size (diameter or length) is between 3 and $8 \mu \mathrm{m}$. The minimum size is about $1.2 \mu \mathrm{m}$ and the maximum size is approximately $12 \mu \mathrm{m}$. A measurement technique based on the automatic processing of SEM images was used to estimate the volume fraction of inclusions. An area of approximately $40 \mathrm{~mm}^{2}$ was scanned for each plane. Around thirty images are processed for each surface, in order to calculate the surface area of the inclusions, $S_{i}$, and the total surface area scanned, $S_{T}$. If a random distribution of inclusions is assumed, it is possible to estimate the volume fraction of inclu-

Table 1

Chemical composition of the HSLA steel investigated.

\begin{tabular}{lllllllll}
\hline Elements & $\mathrm{C}(\% \max )$ & $\mathrm{Mn}(\% \max )$ & $\mathrm{Si}(\% \max )$ & $\mathrm{P}(\% \max )$ & $\mathrm{S}(\% \max )$ & $\mathrm{Al}(\% \max )$ & $\mathrm{Nb}(\% \max )$ & $\mathrm{V}(\% \max )$ \\
\hline Value & 0.12 & 1.70 & 0.50 & 0.025 & 0.015 & 0.015 & 0.09 & 0.20 \\
\hline
\end{tabular}




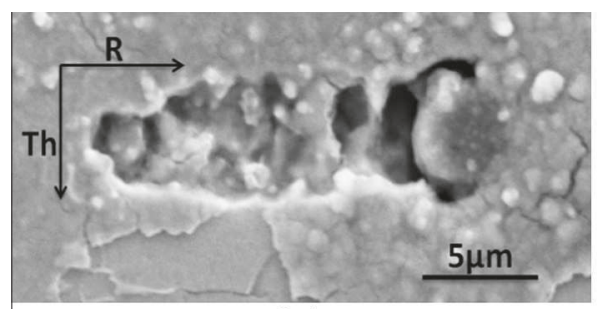

(a)



(c)



(b)

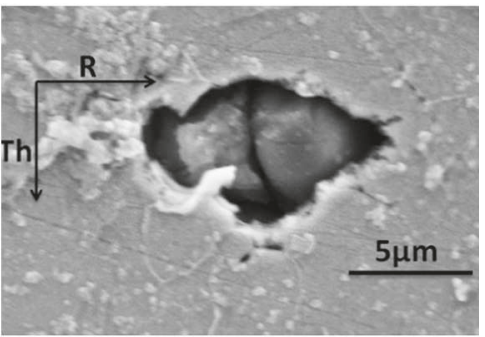

(d)

Fig. 2. Examples of inclusions found in the material: (a) oxide ( $\mathrm{FeO})$, (b) oxide compounds $\left(\mathrm{MgO}^{-} \mathrm{Al}_{2} \mathrm{O}_{3}\right)$, (c) sulfide compounds ( $\left.\mathrm{FeS}-\mathrm{CaS}\right)$ and (d) oxysulfide $\left(\mathrm{Al} \mathrm{O}_{3}-\mathrm{CaS}\right)$.

Table 2

Volume fraction of inclusions for the three orthogonal planes analyzed.

\begin{tabular}{lll}
\hline Surface & Volume fraction of inclusions, $V_{I}$ & Average \\
\hline R-T & 0.0017 & 0.0015 \\
R-Th & 0.0014 & \\
T-Th & 0.0015 & \\
\hline
\end{tabular}

sions $V_{I}$ by assuming that it is equivalent to the surface fraction $S_{I}$ [27].

$V_{I}=S_{I}=\frac{S_{i}}{S_{T}}$

Table 2 summarizes the inclusion volume fraction determined for the three orthogonal planes of the material.

\subsection{Microscopic characterization of ductile fracture mechanisms}

Ductile damage mechanisms are generally attributed to the initiation and growth of micro-defects, which are usually associated with the degradation of macroscopic properties. Micro-cracks and micro-cavities are two major defects in this material. Nucleation, growth and coalescence of these micro-defects are the classically observed damage mechanisms associated with ductile rupture.

In order to observe the evolution of the microstructure and identify the mechanisms of ductile rupture, in situ tensile tests in a SEM have been carried with two different specimen geometries. These geometries are chosen to achieve two different stress states. Fig. 3a shows the two specimen geometries used. These specimens are designed so as to obtain in their zones of interest:

- A high level of stress triaxiality in a tensile stress state.

- Low stress triaxiality due to a shear dominated stress state.

The specimens were machined by wire Electro Discharge Machining (EDM) and have been ground on both sides to obtain a thickness of exactly $2 \mathrm{~mm}$. Loading to failure has been performed using a test device located inside the SEM. Setup and synchronization test have been performed using the software Microtest ${ }^{\circledR}$.

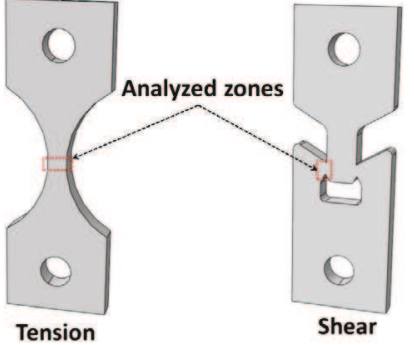

(a)
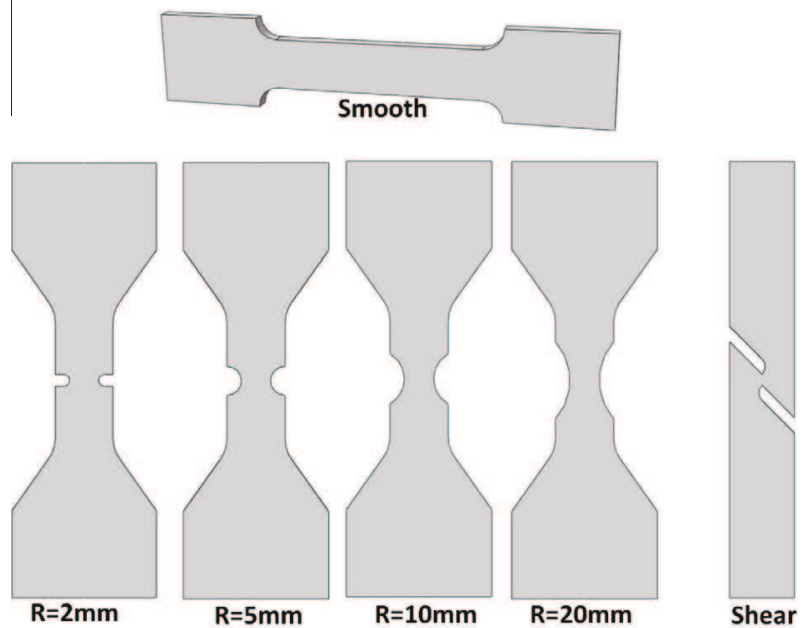

(b)

Fig. 3. Specimen geometries for: (a) in situ specimens and (b) macroscopic specimens.

\subsubsection{Specimen 1 - tensile stress state}

Three specimens were tested in order to analyze the ductile rupture process in a tensile stress state with high stress triaxiality. Fig. 4 shows the evolution of the necking phenomenon during loading of one of the three specimens. The increasing tensile load results in an increase of the edge radius in the test section of the 


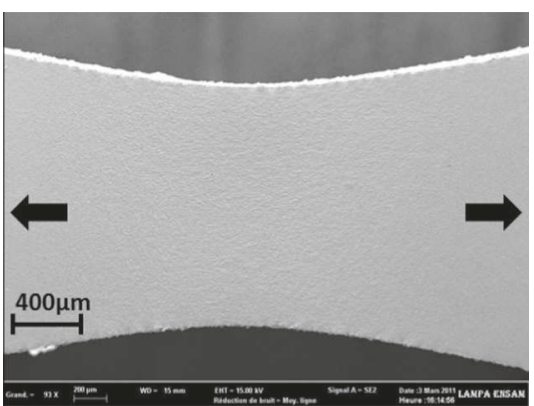

(a)

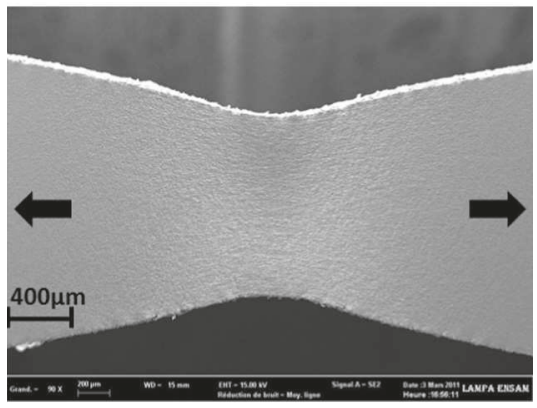

(c)

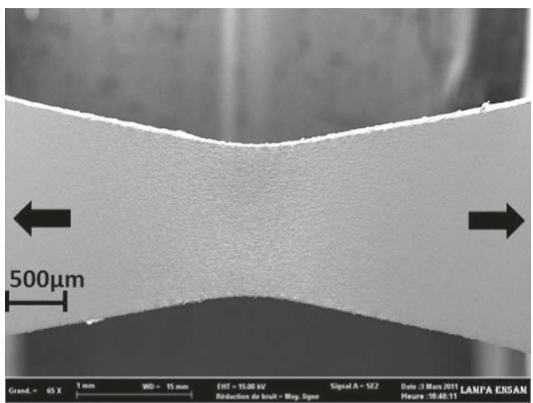

(b)

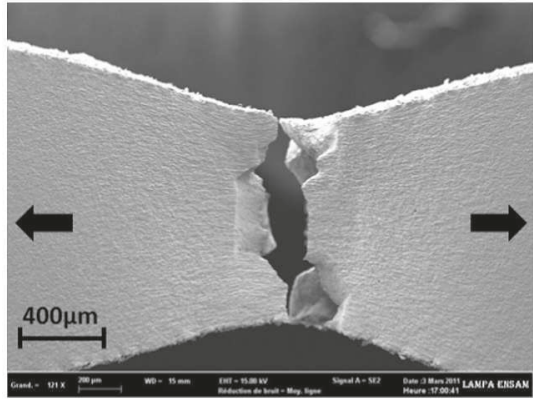

(d)

Fig. 4. Evolution of the necking zone for the in situ tensile tests: (a) just before the necking, (b) the beginning of necking, (c) just prior the fracture and (d) after fracture.
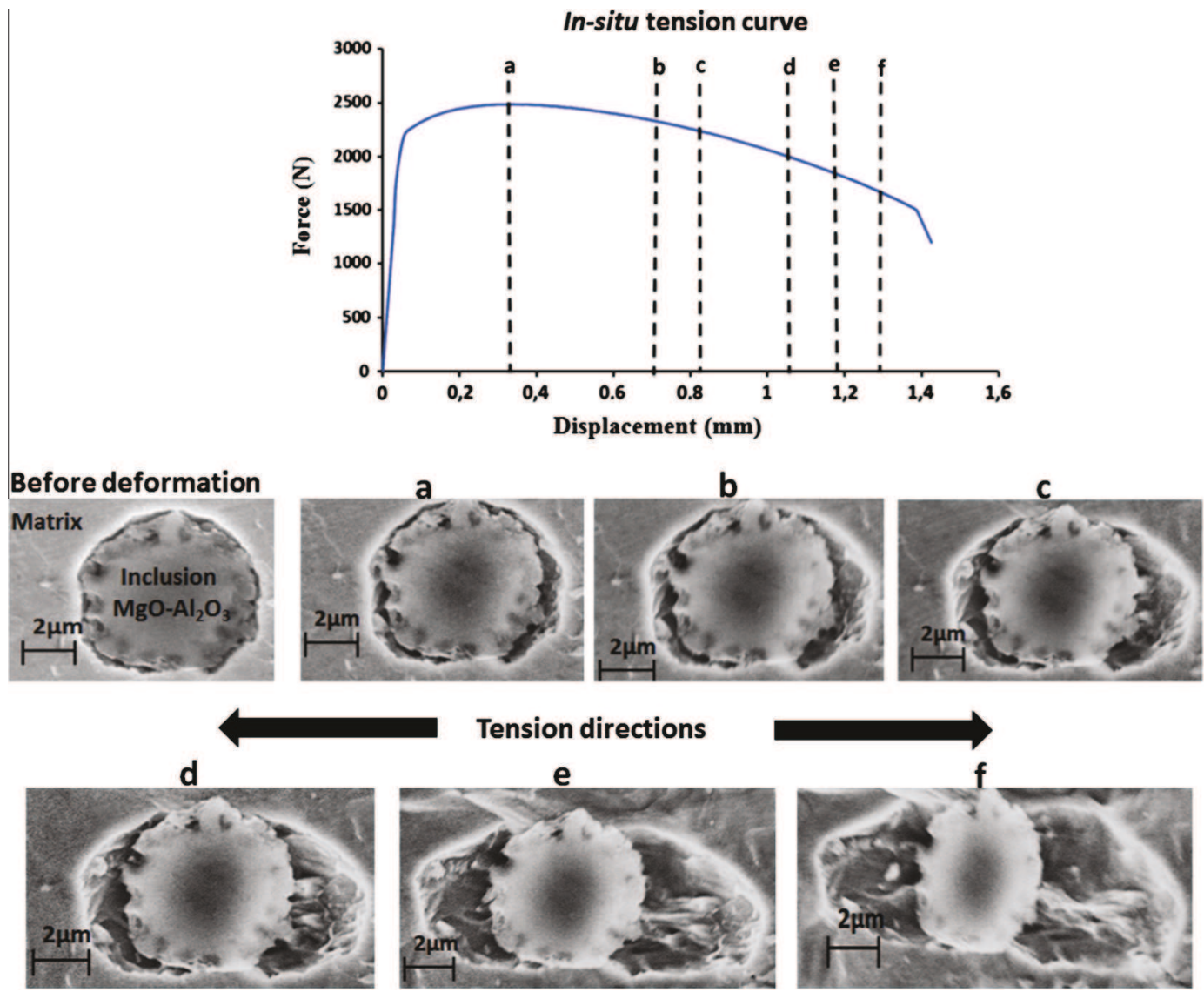

Fig. 5. Void evolution around an inclusion during an in situ tensile test. 
specimen (Fig. 4a). When the load reaches its maximum value, necking appears in the central area of the specimen (Fig. 4b). From this point on, damage accumulates and localizes causing a reduction in thickness (Fig. 4c). Failure finally occurs. The failure surface has a typical ductile rupture profile for a tensile stress state (Fig. 4d).

Fig. 5 shows an example of void evolution around an oxide inclusion $\left(\mathrm{MgO}-\mathrm{Al}_{2} \mathrm{O}_{3}\right)$. It is positioned in the necking region, where the level of stress triaxiality is a maximum. The series of micrographs shown in Fig. 5 were taken at different strain levels.

The incompatibility between the mechanical properties of the matrix material and the inclusion results in the initiation of voids by debonding between the two phases (Fig. 5a). Their growth occurs in a progressive manner in an ellipsoid form, elongated in the loading direction (Fig. 5b-f). This growth increase continuously, with the creation of slip bands and micro-cracks in the matrix (Fig. 6), to a critical level at which the interaction of the cavities leads to the deterioration of the material. This stage corresponds to the mechanism of void coalescence, which is difficult to observe due to the speed at which it occurs.

\subsubsection{Specimen 2 - shear dominated stress state}

\section{- Evolution of the shear zone:}

Fig. 7 shows the evolution of the shear zone during loading. The creation of a shear zone between the two notches can be observed (Fig. 7a). High stresses are located along this zone, which can be characterized by a reduction in thickness. Cracks initiate at the edge of the notch (Fig. $7 \mathrm{~b}$ ) and propagate along the zone until complete fracture of the specimen (Fig. 7c). The rounded area on the edge is typical of fiber reorientation in the two shear directions, thereby creating a burr caused by stretching of the material.
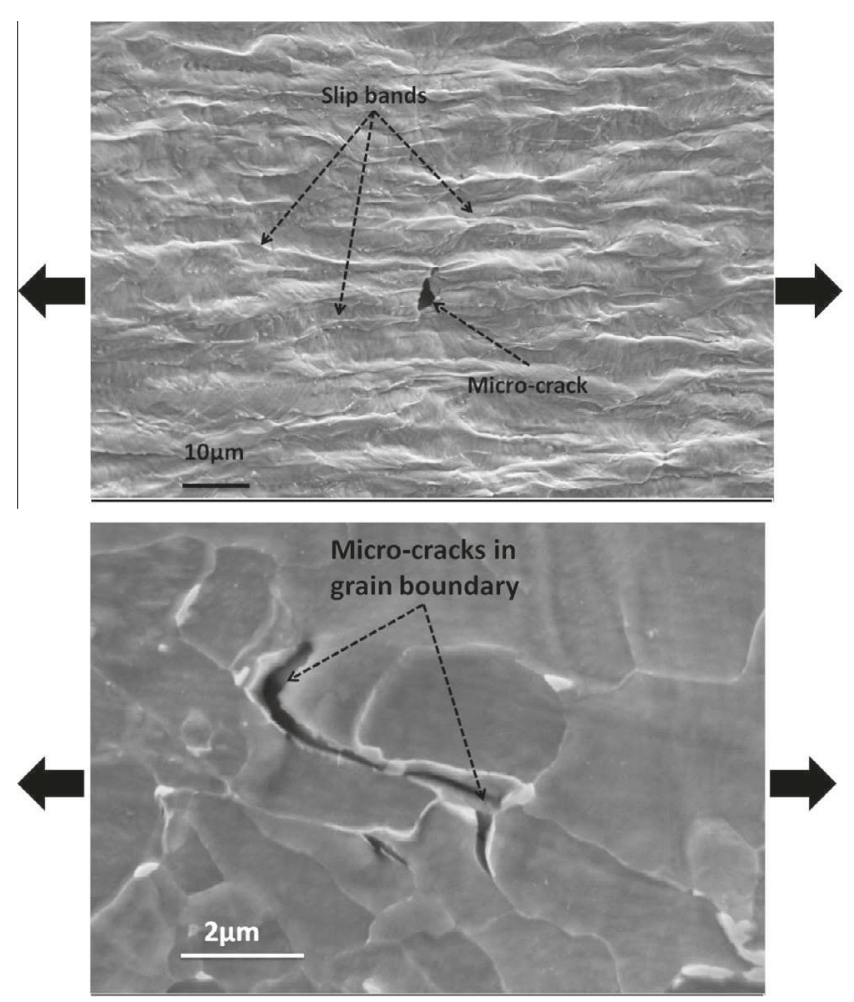

Fig. 6. Damage to the material matrix during in situ tensile tests (at $75 \%$ displacement at fracture).

\section{- Evolution of the matrix:}

Fig. 8 shows an example of micro-cracks in the matrix. The creation of shear bands as a result of strain localization causes the appearance of micro-cracks which extend in the shear directions and form voids in the matrix.

\section{- Evolution of cavities:}

The series of micrographs shown in Fig. 9 demonstrate the evolution (based on the percentage of displacement at fracture) of three voids around three inclusions as a function of load level. These are positioned in two different zones (Fig. 9a). The inclusions located near line 1 are more highly solicited in shear compared to those positioned close to line 2 .

Before loading (Fig. 9b at 0\% displacement at fracture), the inclusions are coherent with the matrix material. Following the onset of deformation due to loading, the difference in stiffness at the matrix/inclusion interfaces, results in stress concentrations, which act as germination sites for voids by debonding between the matrix and inclusions (Fig. 9b at 88\%). A second mechanism for cavity nucleation can be seen at line 2 . It is characterized by the fragmentation of inclusions and does not involve the debonding mechanism (Fig. 9d). Some inclusions located near line 1 underwent a combination of these two mechanisms: debonding and fragmentation as shown in Fig. 9c. The growth of voids is controlled by plastic flow which causes hardening of the matrix around the inclusions. The growth is not uniform and depends strongly on the stress state and the shape of the voids, which is different from that observed in tension. Some voids tend to grow in both shear directions, forming angular points or "corners". Deformed voids also undergo a rotation that depends on the loading level. When the material between two voids is small enough, interactions between the voids occur. Plastic flow in the material between the voids then generates a shear fracture of the material. The acceleration in the evolution of the void volume fraction, which characterizes the coalescence stage, is associated with the initiation of a macroscopic crack at the notch of the specimen (Fig. 7). The propagation of the macroscopic crack along the shear zone leads to the complete fracture of the specimen.

\subsection{Macroscopic tests}

Mechanical tests with different specimen shape have been performed to characterize the effects of stress state on damage evolution and the ductile rupture mode. Six series of tests have been carried out.

\subsubsection{Tensile tests}

Tensile tests were undertaken on both notched and un-notched (Fig. 3b) specimen with rectangular cross-sections. The loading axis of the specimens is parallel to the sheet rolling direction. Four notch radii have been tested: $R=20 \mathrm{~mm}, R=10 \mathrm{~mm}, R=5 \mathrm{~mm}$ and $R=2 \mathrm{~mm}$. All tests have been carried out on an INSTRON 8801 hydraulic testing machine with maximum load capacity of $100 \mathrm{kN}$. The tests were performed in displacement control at a constant speed of $0.5 \mathrm{~mm} / \mathrm{min}$. An extensometer with an initial length of $l_{0}=25 \mathrm{~mm}$ was used (except for the $R=2 \mathrm{~mm}$ notched specimens, for which an initial extensometer length of $l_{0}=12.5 \mathrm{~mm}$ was used). For each configuration, four tests were done. The displacement measurement error at fracture is approximately $2 \%$ for each specimen type. The engineering stress-strain curves are determined via the usual relationships, whereby the engineering stress is $\sigma_{\text {eng }}=F / S_{0}$ and the engineering strain is $\varepsilon_{\text {eng }}=\Delta l / l_{0}$, where $S_{0}$ is the initial cross-sectional area of the specimen. 


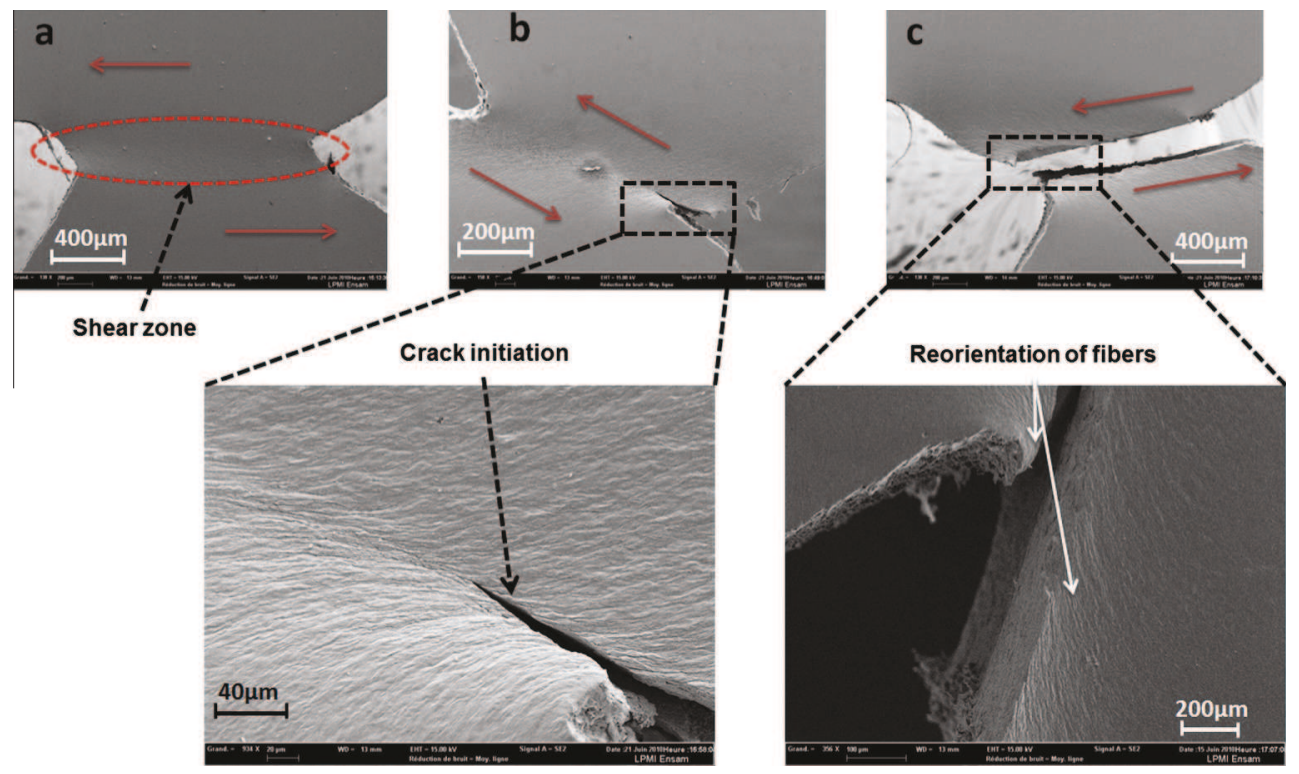

Fig. 7. Evolution of the shear zone for in situ specimens loaded to rupture.

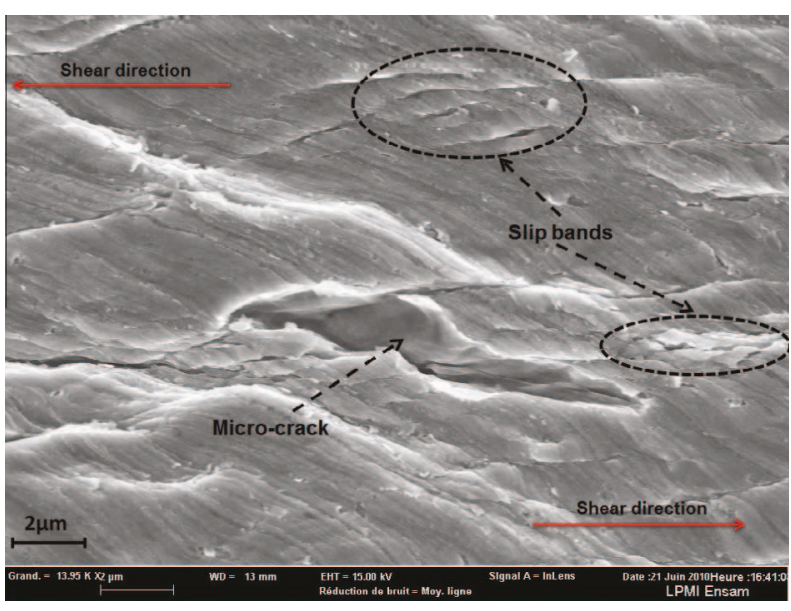

Fig. 8. Evolution of the material matrix during in situ shear tests.

The mechanical properties obtained from averaging the four tests are summarized in Table 3. This material is characterized by an elongation at fracture that is relatively high and significant necking.

Note: For reasons of confidentiality, imposed by our industrial partner, the results given below have been normalized by the maximum values of each variable (stress, strain, force, displacement, etc.).

Fig. 10 shows the normalized force-displacement curves determined from tensile tests on notched specimens. Three experimental parameters can be identified from these experiments: the displacement at fracture $d_{r}$, the maximum force $F_{\max }$ and the fracture strain given by:

$\varepsilon_{r}=\ln \left(\frac{S_{0}}{S_{r}}\right)$

where $S_{0}$ is the initial cross-sectional area of the specimen and $S_{r}$ is the final cross-sectional area at fracture, which is measured postmortem using an SEM.
The value of displacement at fracture, which corresponds to the appearance of the first macroscopic crack, is assumed to be associated with the start of the rapid drop in the force-displacement curve. Table 4 summarizes the normalized values of the parameters determined experimentally by tensile tests on notched specimens.

It can be seen that an increase in the notch radius results in an increase in the fracture displacement $d_{r}$ and the rupture strain, $\varepsilon_{r}$. It also causes a decrease in the maximum force $F_{\max }$.

\subsubsection{Shear tests}

Shear tests result in zero or very low hydrostatic stress compared to the equivalent stress in the fracture zones. In order to study the effect of the stress state for low stress triaxiality, a new test configuration, shown in Fig. 3b, has been developed. Preliminary numerical simulations were performed so as to determine a specimen shape that results in shear band localization in the center of the specimen where the stress triaxiality is close to zero.

These new shear specimens were tested on a Zwick Z100 tensile testing machine, equipped with an extensometer with an initial length of $40 \mathrm{~mm}$. Three specimens have been tested with a crosshead speed of $0.5 \mathrm{~mm} / \mathrm{min}$. The measurement error of the displacement at fracture is about $1.7 \%$.

\subsection{Fractographic analysis}

Fig. 11 shows micrographic images of the fracture surface of tested specimens. It can be seen that on a microscopic scale different rupture morphologies occur in the central area of the specimen.

Fig. 11a shows the failure surface of an un-notched specimen with a rough appearance given by the presence of ductile dimples and micro-voids. This type of morphology occurs in an area limited to the center of the specimen and is typical of ductile tearing.

A second failure mode occurs in the zone referred to as the "ductile lips". These zones are characterized by a surface which is less rough and are located near the edges of the fracture surface. This fracture mode, which corresponds to a zone of shear strain localization, is associated with voids oriented at $45^{\circ}$ which correspond to the plane of maximum shear stress. 


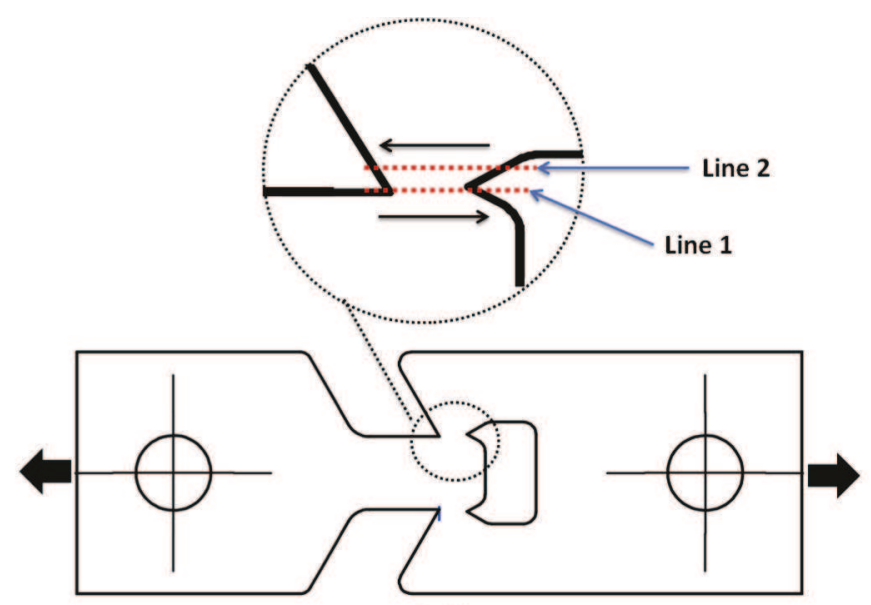

(a)
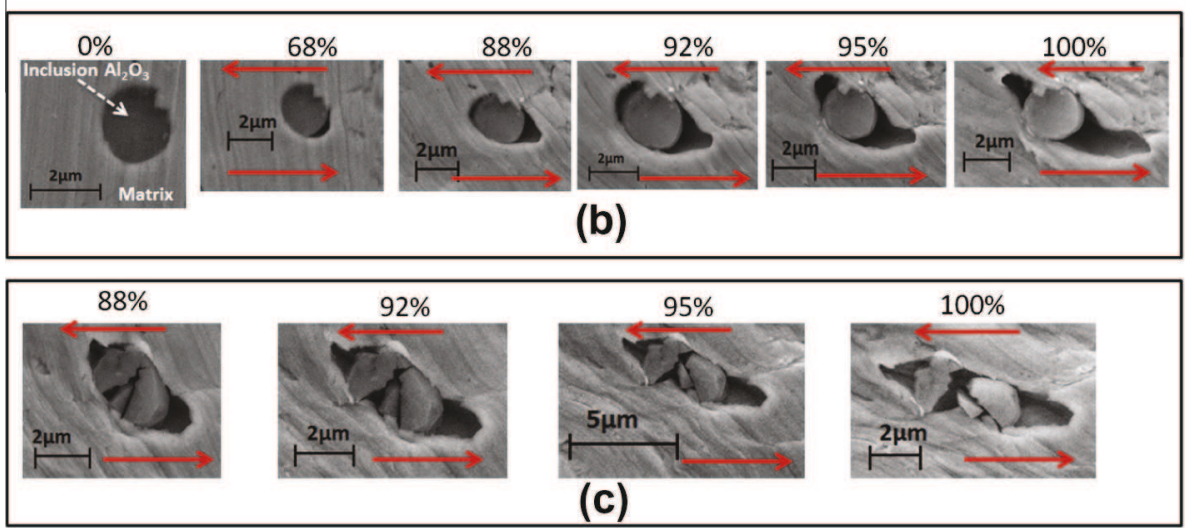

(c)

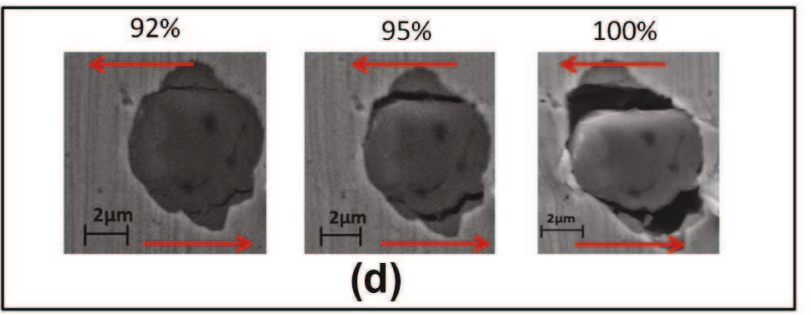

Fig. 9. The evolution of the void nucleation and elongation mechanisms as a function of strain in the shear zone: (a) the location of the inclusions investigated, (b) void nucleation by debonding in the zone defined by line 1 , (c) void nucleation by debonding and fragmentation in the zone defined by line 1 and (d) void nucleation by fragmentation in the zone defined by line 2 .

Table 3

Mechanical properties of the material.

\begin{tabular}{lllll}
\hline Propriety & $E(\mathrm{GPa})$ & $\sigma_{Y}(\mathrm{MPa})$ & $\sigma_{\text {UTS }}(\mathrm{MPa})$ & $A_{r}(\%)$ \\
\hline Value & 210 & 580 & 700 & 22 \\
\hline
\end{tabular}

For notched specimens with a notch radius of $R=20 \mathrm{~mm}$ (Fig. 11b), the distribution of ductile dimples around the microcracks is more obvious compared to the shear fracture plane. The ductile dimples around the micro-cracks are more numerous and closely spaced compared to the smooth tensile specimens.

Fig. 11c shows the fracture surface of a notched specimen with a radius of $R=2 \mathrm{~mm}$. It can be seen that a crack occurs in the center of the fracture surface accompanied by a greater distribution of the ductile dimples. In contrast, the effects of shear fracture are less sensitive than for the smooth specimens or notched specimens with $R=20 \mathrm{~mm}$.

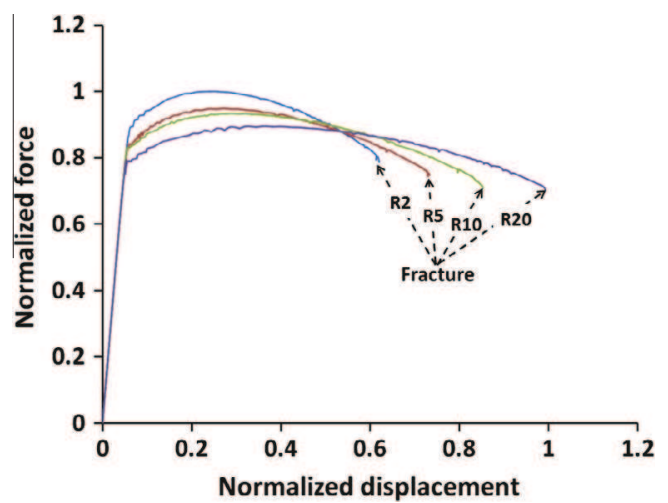

Fig. 10. Normalized force-displacement curves for tensile tests on notched specimens. 
Table 4

Tensile properties of the notched specimens.

\begin{tabular}{lllll}
\hline & $R=2 \mathrm{~mm}$ & $R=5 \mathrm{~mm}$ & $R=10 \mathrm{~mm}$ & $R=20 \mathrm{~mm}$ \\
\hline$d_{\mathrm{r}}$ (normalized) & 0.63 & 0.73 & 0.86 & 1 \\
$F_{\max }$ (normalized) & 1 & 0.95 & 0.93 & 0.89 \\
$\varepsilon_{r}$ (normalized) & 0.69 & 0.74 & 0.89 & 1 \\
\hline
\end{tabular}

For the shear test, shown in Fig. 11d, only a few, very small ductile dimples can be seen on the fracture surface (of size close to zero). Those that can be seen are oriented in the direction of the smooth shear fracture surface.

This variety in the morphology of the fracture surfaces is due to the influence of the stress state on the fracture mode. An increase in stress triaxiality (i.e. notched specimens with $R=2 \mathrm{~mm}$ ) causes an increase in the percentage of ductile dimples in the central area of the fracture surface, which promotes crack initiation. A decrease in the stress triaxiality (i.e. shear specimens and smooth tensile specimens) favors the creation of ductile dimples oriented in the direction of the shear plane and result in ductile fracture by shear.

These observations confirm that the volume fraction of voids (or ductile dimples) $f$ estimated by analyzing the microstructure and morphology of fracture surface is a good indicator of the failure mode. It also highlights that void evolution is sensitive to the stress state and the equivalent plastic strain, as other authors have reported [28].

\subsection{Conclusion}

The following conclusions can be made from the experimental study presented above:

- Microscopically: the in situ tests highlighted a remarkable difference between the physical damage mechanisms observed when the material is subjected to tensile and shear stress states. For tensile loads, the ductile damage process is essentially based on the nucleation and growth of ellipsoid voids oriented in the loading directions. For shear loads, the damage mechanisms are based on the fragmentation and/or the debonding of inclusions from the matrix, followed by the elongation and rotation of the voids. For the two loading types, the void coalescence mechanism is defined by the interaction between microdefects (i.e. the interaction between multiple voids and/or voids and micro-cracks).

- Macroscopically: mechanical tensile tests (on both smooth and notched specimens) and shear tests have been used to determine, for each configuration, the effect of stress state on the fracture strain. Indeed, high stress triaxiality is associated with a decrease in the fracture strain (or the displacement at fracture).

- Fractographic analysis of the fracture surfaces has shown that the stress state also has an influence on the fracture surface morphology and the fracture mode.

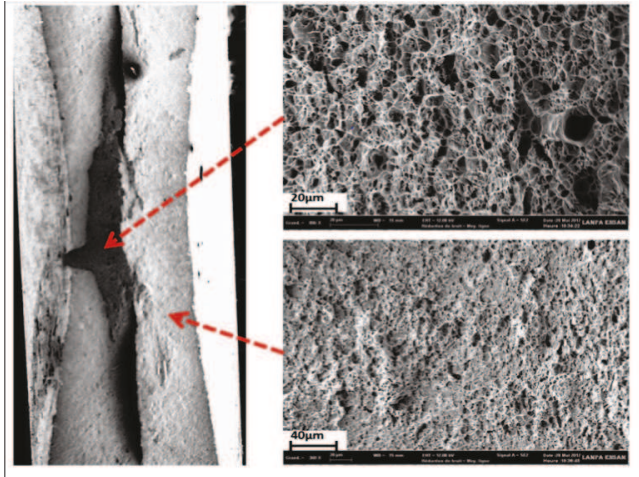

(a)

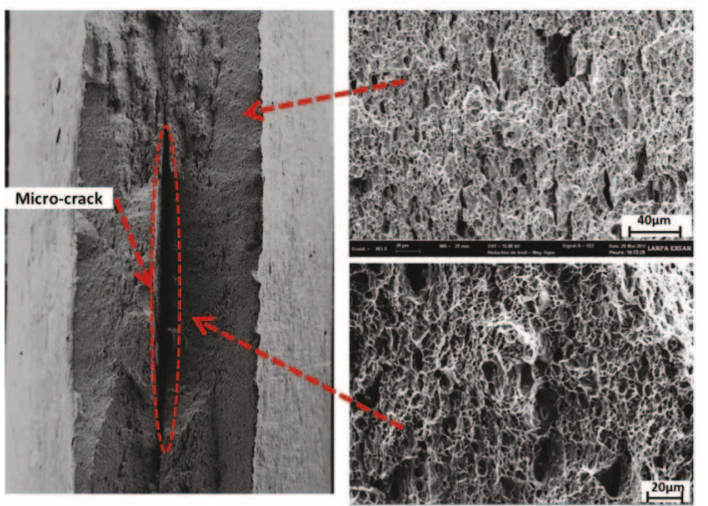

(c)

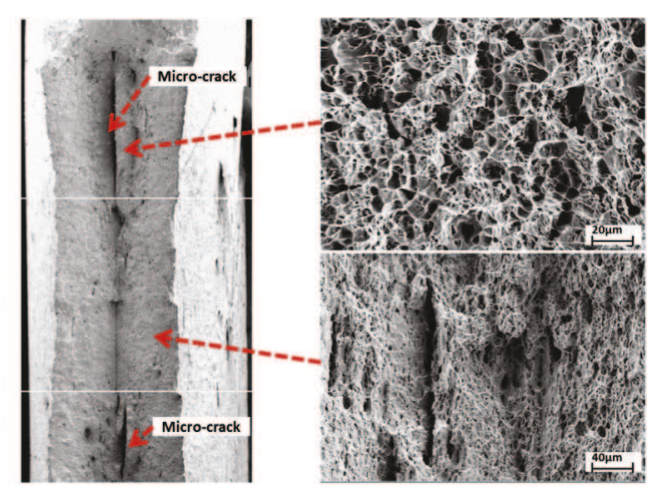

(b)

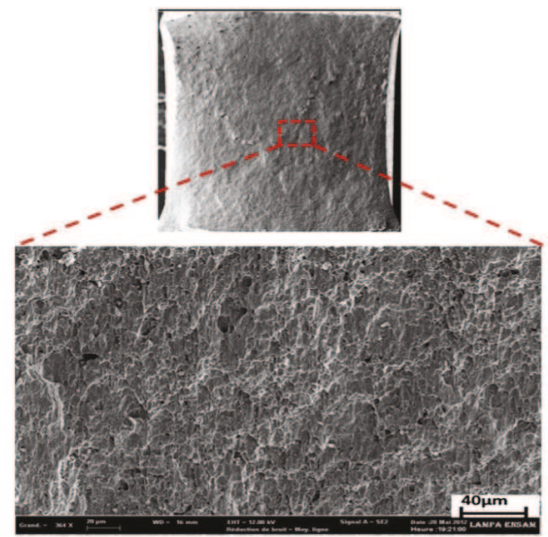

(d)

Fig. 11. Sem images of the failure surfaces of macroscopic specimens: (a) a smooth tensile specimen, (b) a notched tensile specimen $(R=20$ mm), (c) a notched tensile specimen $(R=2 \mathrm{~mm})$ and $(\mathrm{d})$ a shear specimen. 
The experimental data from these tests will be used in the following sections to identify and calibrate the constitutive parameters of the material.

\section{Numerical modeling of ductile damage}

\subsection{Constitutive equations}

\subsubsection{The Gurson-Tvergaard-Needleman model}

In 1977, Gurson [22] proposed a yield surface based on the growth of spherical voids. This model is commonly used to describe the evolution of micromechanical damage in ductile materials. In 1984, Tvergaard and Needleman [5] modified the Gurson model by introducing two additional material parameters $\left(q_{1}\right.$ and $\left.q_{2}\right)$.

Yield surface proposed by Gurson-Tvergaard-Needleman (GTN) has the following form:

$\Phi=\left(\frac{q}{\sigma_{0}}\right)^{2}+2 q_{1} f^{*} \cosh \left(-\frac{3 q_{2} p}{2 \sigma_{0}}\right)-\left(1+q_{1}^{2} f^{* 2}\right)=0$

where $\sigma_{0}$ is the flow stress of the material, $q=\sqrt{(3 / 2) s: s}$ is the von Mises equivalent stress with $\mathrm{s}$ is the deviatoric stress tensor and $p=-\operatorname{trace}(\sigma) / 3$ is the hydrostatic stress. $f^{*}$ is the effective void volume fraction used to simulate the void coalescence $\left(f^{*}=f^{*}(f)\right)$, where $f$ is the void volume fraction proposed by Gurson [22].

$f^{*}= \begin{cases}f & \text { for } f \leq f_{c} \\ f_{c}+\left(f-f_{c}\right) \frac{f_{u}-f_{c}}{f_{f}-f_{c}} & \text { for } f>f_{c}\end{cases}$

$f_{c}$ is the critical void volume fraction associated with the void coalescence phase, $f_{u}=1 / q_{1}$ is the ultimate void volume fraction and $f_{f}$ represent the void volume fraction at fracture.

The evolution of the total void volume fraction is given by:

$\dot{f}=\dot{f}_{\text {growth }}+\dot{f}_{\text {nucleation }}$

The void growth rate is defined a function of the plastic strain rate, and takes the following form:

$\dot{f}_{\text {growth }}=(1-f) \operatorname{tr}\left(\dot{\varepsilon}^{p}\right)$

$\dot{\varepsilon}^{p}$ is the plastic strain rate tensor.

The second quantity, in Eq. (5), takes into account void nucleation and can be written as:

$\dot{f}_{\text {nucleation }}=A \dot{\bar{\varepsilon}}^{p}$

Nucleation of new cavities is taken to be governed by a normal distribution as suggested by Chu and Needleman [30], so that the coefficient $A$ in Eq. (7) takes the form:

$A= \begin{cases}\frac{f_{N}}{S_{N} \sqrt{2 \pi}} \exp \left[-\frac{1}{2}\left(\frac{\bar{c}^{p}-\varepsilon_{N}}{S_{N}}\right)^{2}\right] & \text { for } \quad p \geqslant 0 \\ 0 & \text { for } \quad p<0\end{cases}$

where $f_{N}$ is the quantity of voids nucleated per unit volume, $\varepsilon_{N}$ is the nucleation strain and $S_{N}$ is corresponding standard deviation.

For low stress triaxiality $(\eta=-p / q)$, the Gurson model is unable to predict the void growth rate. This issue is the subject of a recent modification of the GTN model, proposed by Nahshon and Hutchinson [25]. This modification introduces a phenomenological term that models the distortion and reorientation of voids dominated by shear stresses. This phenomenon was observed and discussed in Section 2.3.2.

\subsubsection{Modified GTN model in shear loading}

The new expression introduced by Nahshon and Hutchinson [25] is: $\dot{f}_{\text {shear }}=k_{w} \frac{f w_{0}(\sigma)}{q} S: \dot{\varepsilon}^{p}$

where $w_{0}(\sigma)$ is a function of the stress state, characterized by the normalized third invariant of the deviatoric stress tensor $\left(\xi=27 \mathrm{~J}_{3}\right.$ / $\left.2 q^{3}\right)$. The function $w_{0}(\sigma)$ is given by:

$w_{0}(\sigma)=w(\xi)=1-(\xi)^{2}$

where $J_{3}=\operatorname{det}(s)$ is the third invariant of the deviatoric stress tensor, $s=\sigma+p I$. $I$ is the unit tensor.

The parameter $k_{w}$ in Eq. (9) is the magnitude of the damage growth rate in shear. $w_{0}(\sigma)$ is formulated to make a distinction between stress state without shear (i.e. where $w_{0}(\sigma) \approx 0$ ) and all stress states describing the combined effects between pure shear and hydrostatic pressure (where $w_{0}(\sigma) \approx 1$ ).

However, this approach can have a significant influence on some stress states with high levels of stress triaxiality. For example, this is the case for uniaxial tension in a state of plane strain, where the stress triaxiality is approximately 0.577 . In this case, the third invariant of the stress tensor $\xi$ is zero and thus $w_{0}(\sigma) \approx 1$. The contribution to the development of shear damage is maximized, despite a high level of stress triaxiality.

To overcome this drawback, Nielsen and Tvergaard [26] have proposed another improvement to the model by introducing an additional factor, $\Omega(\eta)$, in the shear damage evolution term, which depends on the level of stress triaxiality. For this, $w_{0}(\sigma)$ is expressed in following form:

$W_{0}(\sigma)=w(\xi) \Omega(\eta), \quad$ with $\quad \Omega(\eta)= \begin{cases}1, & \text { for } \eta<\eta_{1} \\ \frac{\eta-\eta_{1}}{\eta_{1}-\eta_{2}}, & \text { for } \eta_{1} \leqslant \eta \leqslant \eta_{2} \\ 0, & \text { for } \eta>\eta_{2}\end{cases}$

where $\eta_{1}<\eta_{2}$ and $w(\xi)$ are given by Eq. (10). This implies that the Hutchinson and Nahshon model is used for $\eta \leqslant \eta_{1}$, while the GTN model is used for $\eta \geqslant \eta_{2}$.

With the proposed extension, given in Eq. (11), the characteristics of the GTN model are maintained for high stress triaxiality, while at the same time conserving the improvements for ductile shear fracture with low stress triaxiality.

Finally, after the addition of the new contribution for shear loads, $\dot{f}_{\text {shear }}$, the evolution of the total void volume fraction becomes:

$\dot{f}=(1-f) \operatorname{tr}\left(\dot{\varepsilon}^{p}\right)+A \dot{\bar{\varepsilon}}^{p}+k_{w} \frac{f w(\sigma)}{q} S: \dot{\varepsilon}^{p}$

\subsection{Finite element models}

This improved Gurson model for shear loading conditions has been implemented [31] in the ABAQUS/Explicit finite element code, using a VUMAT subroutine [29].

The central zone of the specimens is meshed with 3D solid elements with eight nodes using reduced integration (type C3D8R). The rest of the specimen is meshed with tetrahedral solid elements. For both the smooth and notched tensile specimens the planes of symmetry are exploited so that only one quarter of the specimen is modeled. For the shear specimens, the complete specimen is modeled. The mesh size in the fracture zone is $100 \mu \mathrm{m}$. This mesh size is compatible with the average spacing between inclusions, determined via microscopic analysis. Fig. 12 shows the mesh used for the three specimen types. 


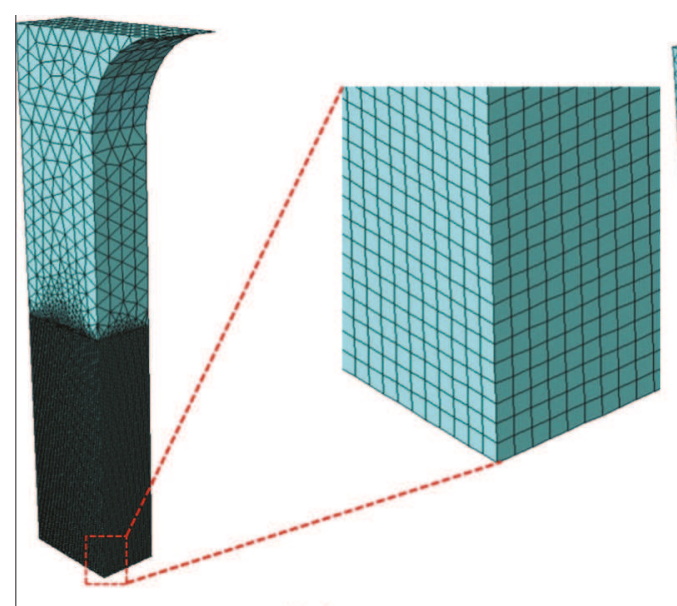

(a)

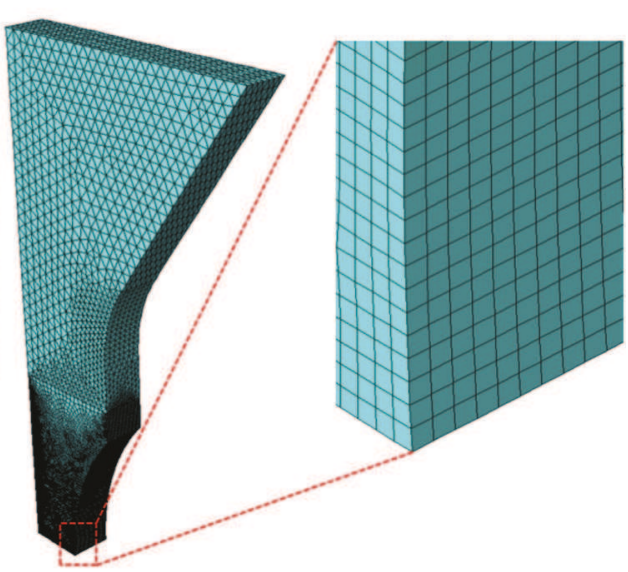

(b)

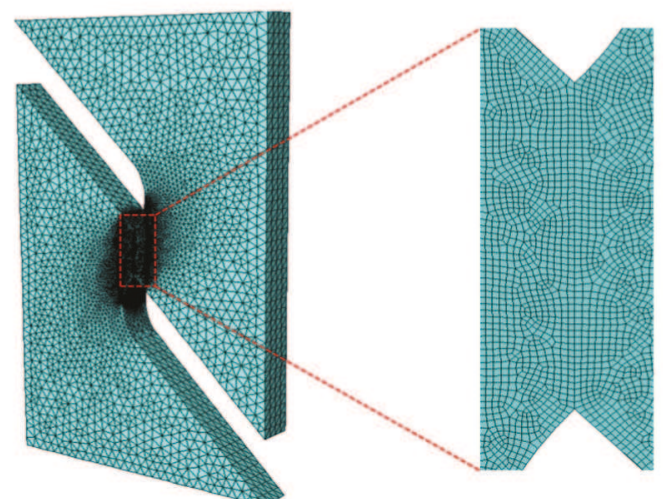

(c)

Fig. 12. The finite element mesh used for each test type: (a) smooth tensile specimens, (b) notched tensile specimens $(R=20 \mathrm{~mm})$ and (c) shear specimens.

\subsection{Identification of material parameters}

The modified Gurson model, implemented in ABAQUS/Explicit, requires the identification of fourteen material parameters. These are:

- The hardening parameters: $\sigma_{y}, K$ and $n$.

- The macroscopic coefficients of the yield surface: $q_{1}$ and $q_{2}$.

- The initial void volume fraction $f_{0}$, the void volume fractions associated with coalescence $f_{c}$ and fracture $f_{f}$.

- The void nucleation parameters: $\varepsilon_{N}, S_{N}$ and $f_{N}$

- The shear damage parameters: $k_{w}, \eta_{1}$ and $\eta_{2}$.

The use of tensile tests on smooth specimens, to simultaneously calibrate the hardening and damage parameters, is insufficient to predict ductile rupture of the material over a wide stress triaxiality range [32]. Consequently, the material parameters are determined using three tests: (1) uniaxial tensile tests on smooth specimens (2) uniaxial tensile tests on notched specimen $(R=20 \mathrm{~mm})$ and (3) shear tests. An inverse method is then used to identify the parameters, via comparison between the experimental and numerical force-displacement curves.

\subsubsection{The initial void volume fraction}

The initial voids volume fraction has been determined from microstructural observations (Section 2.2) and methods recommended in the literature [27,33-35]. In this work, the initial void

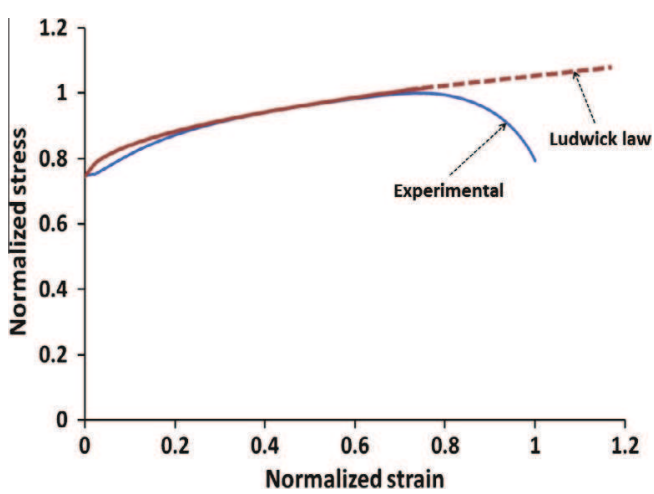

Fig. 13. Comparison between the Ludwick hardening law and the experimental stress-strain curve.

volume fraction is estimated by the inclusions volume fraction, which corresponds to $f_{0}=0.0015$.

\subsubsection{The hardening parameters}

The Ludwick equation has been used to model the material hardening:

$\sigma_{0}=\sigma_{y}+K\left(\bar{\varepsilon}^{p}\right)^{n}$

The hardening parameters: $\sigma_{y}=580 \mathrm{MPa}$ (the initial yield stress), $K=560 \mathrm{MPa}$ (the hardening coefficient) and $n=0.51$ (the hardening exponent) are obtained by a best fit of Eq. (13) with 
the experimentally determined true stress-strain curves for tensile tests on smooth specimens, up to the point of necking. Fig. 13 shows the comparison of the true stress-strain curve with the Ludwick equation.

\subsubsection{The void nucleation parameters}

The nucleation strain $\varepsilon_{N}$ and the volume fraction of nucleated voids $f_{N}$ are chosen to optimize the predictions for the maximum strength and the decrease in strength after necking. This is done based on the experimental notched tensile test results $(R=20 \mathrm{~mm})$. A standard deviation of $S_{N}=0.1$ is chosen for the void nucleation law. Fig. 14a shows the influence of the strain nucleation value $\varepsilon_{N}$ on the maximum force (vertical dashed lines). It can be concluded that increasing the value of $\varepsilon_{N}$ shifts the position of the maximum force in the direction of increasing displacement. This corresponds to the start of the loss of rigidity of the material. The best agreement with the experimental curve is obtained for a strain nucleation value of $\varepsilon_{N}=0.2$. Similarly, the volume fraction of nucleated voids $f_{N}$ influences the position of the loss of rigidity of the material given by the chute in the force/displacement curve after the maximum force (Fig. 14b). The best agreement with the experimental curve is obtained for $f_{N}=0.02$.

\subsubsection{The yield surface coefficients: $q_{1}$ and $q_{2}$}

For moderate hardening $(n=0.1)$, Tvergaard [36,37] found that values $q_{1}=1.5$ and $q_{2}=1$, give the best fit with results obtained by the cell model. Koplilik and Needleman [38] proposed new values of $q_{1}=1.25$ and $q_{2}=1$ which provide good agreement with the results of numerical simulations using the GTN model. Other values of $q_{1}$ and $q_{2}$ have been also proposed by Brocks [39]. Faleskog et al. [40] have shown that the ultimate strength and hardening influ-

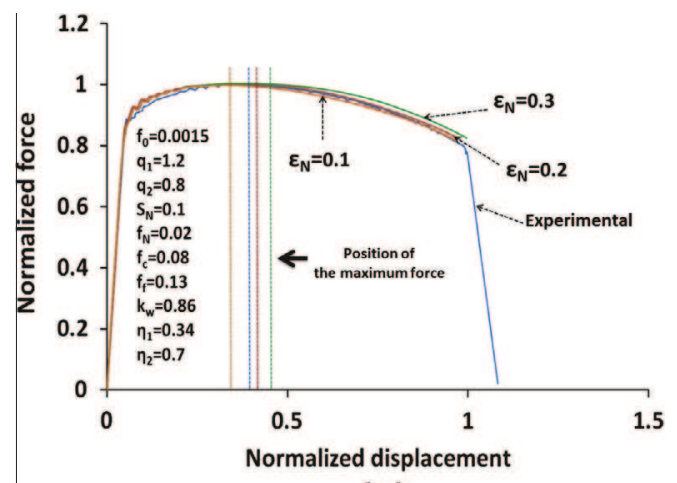

(a)

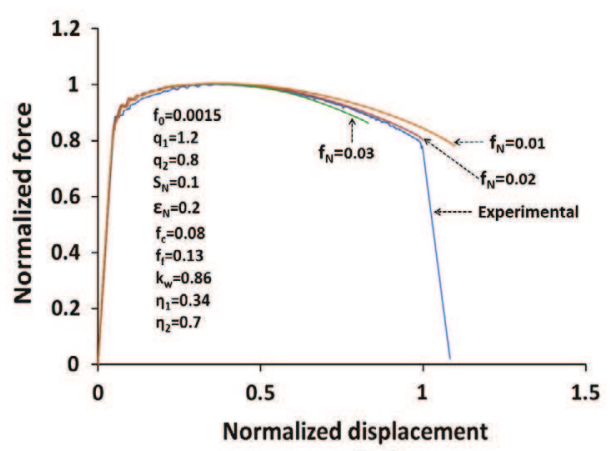

(b)

Fig. 14. Influence of (a) the nucleation strain $\varepsilon_{N}$ and (b) the void volume fraction at nucleation $f_{N}$ on the prediction of the force-displacement curve for tensile tests on notched specimens $(R=20 \mathrm{~mm})$. ence the values of $q_{1}$ and $q_{2}$. In addition, Kim et al. [13] have shown that $q_{1}$ and $q_{2}$ depend on the stress triaxiality and the initial void volume fraction. Recently, Dunand and Mohr [41] have showed that the values of $q_{1}=1$ and $q_{2}=0.7$, identified from a punching test, provide numerical predictions that are in good agreement with experimental results.

Finally, it should be noted that all authors highlight the fact that the parameters $q_{1}$ and $q_{2}$ have a significant influence and can be used to improve the predictions from the GTN damage model.

Since $q_{1}$ and $q_{2}$ play the same role as the nucleation parameters, in terms of the loss of rigidity in the force-displacement curve, the shear test was chosen to calibrate $q_{1}$ and $q_{2}$. Fig. 15 shows the comparison between the experimental curve and the simulation results, for three parameter sets: $\left[q_{1}=1.5 ; q_{2}=1\right]$, $\left[q_{1}=1.25 ; q_{2}=1\right]$ and $\left[q_{1}=1.2 ; q_{2}=0.8\right]$. The best agreement with the experimental curve is obtained with $q_{1}=1.2$ and $q_{2}=0.8$ while at the same time respecting the prediction of the force-displacement curve obtained by tensile tests on notched specimens with $R=20 \mathrm{~mm}$.

\subsubsection{The critical void volume fraction $f_{c}$ and the void volume fraction at fracture $f_{f}$}

The critical void volume fraction $f_{c}$ is the value at which material damage begins to grow rapidly due to void coalescence. Decreasing $f_{c}$ allows the material to rapidly achieve this initiation point [42]. Fig. 16a shows the influence of different $f_{c}$ values on the initiation point of void coalescence for tensile test on notched specimens with $R=20 \mathrm{~mm}$. A value $f_{c}=0.08$ gives the best agreement with the experimental curve.

The void volume fraction at fracture $f_{f}$ is associated with the complete loss of material stiffness. Reducing the value of $f_{f}$ leads to an earlier drop in rigidity associated with a very steep negative slope. The void volume fraction at fracture represents the end of the coalescence phase. Fig. 16b shows the effect of $f_{f}$ on the predictions obtained from tensile test simulations of notched specimen with $R=20 \mathrm{~mm}$. The value $f_{f}=0.13$ results in a good prediction for the final fracture of the material with the respect of the fracture initiation point.

\subsubsection{Shear damage parameter $k_{w}$}

The shear damage parameter $k_{w}$ has been calibrated using the shear test. Fig. 17 shows the force-displacement curves for two values of $k_{w}$. As expected, there is no shear damage predicted for the case of $k_{w}=0$ where the damage model coincides with the clas-

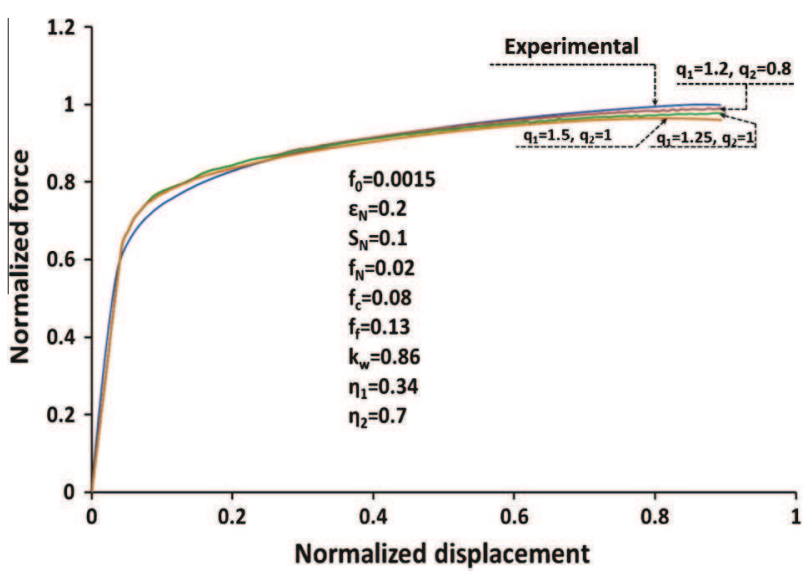

Fig. 15. Influence of the parameters $q_{1}$ and $q_{2}$ on the prediction of the forcedisplacement curve for shear tests. 
sical model of GTN. A good correlation with experimental results is observed for $k_{w}=0.86$.

Note: It is interesting to note that the coefficients of the nucleation law and the coefficients $q_{1}$ and $q_{2}$ have a similar influence on the prediction of the force-displacement curve. Consequently, it is necessary to use different tests to calibrate these parameter sets. In addition, each calibration step is not independent of all subsequent steps. For example, the results of numerical simulation in Fig. 15 depend on the values of the parameters $q_{1}$ and $q_{2}$. The calibration

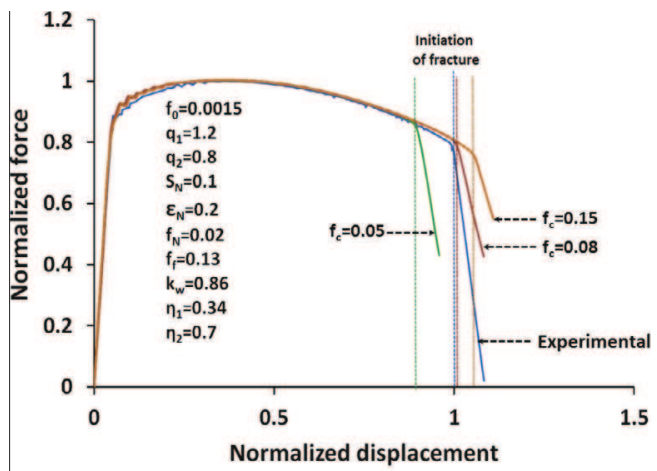

(a)

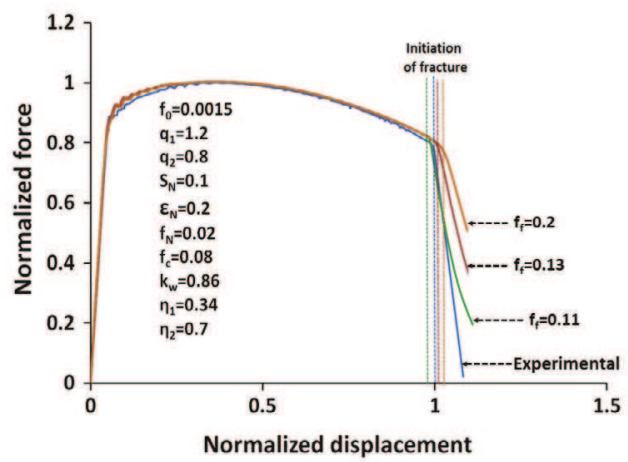

(b)

Fig. 16. Influence of (a) the critical void volume fraction $f c$ and (b) the final void volume fraction $f_{f}$ on the prediction of the force-displacement curve for tensile tests on notched specimen $(R=20 \mathrm{~mm})$.

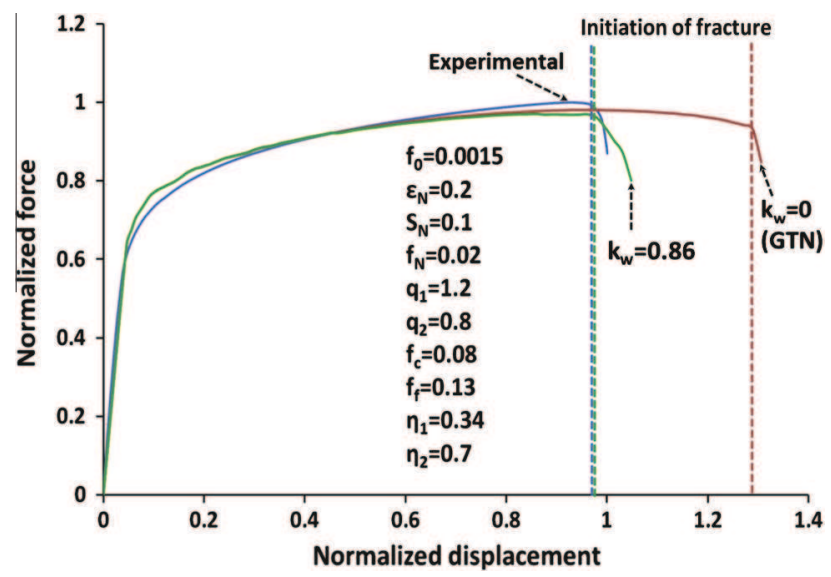

Fig. 17. Influence of the shear damage parameter $k_{w}$ of the prediction of the forcedisplacement curve for shear tests. procedure has been repeated iteratively until the numerical curves are consistent with the experimental curves.

\subsubsection{Weights coefficients ( $\eta 1$ and $\eta 2$ ) proposed by Nielsen and Tvergaard}

The tensile tests on notched specimen with $R=20 \mathrm{~mm}$ are used to identify the coefficients $\eta_{1}$ and $\eta_{2}$ which control the activation of the shear damage accumulation term. Fig. 18 shows the curves obtained with the Nielsen and Tvergaard extension and the improvement proposed by Nahshon and Hutchinson. The displacement at fracture is correctly predicted with $\eta_{1}=0.34$ and $\eta_{2}=0.7$. The activation of the shear damage accumulation term (i.e. the Nahshon and Hutchinson extension) affects only slightly the fracture prediction for tensile test on specimen with $R=20 \mathrm{~mm}$. It is important to note that this test is particularly suitable for the calibration of $\eta_{1}$ and $\eta_{2}$. In fact, the stress triaxiality increases continuously from $\eta_{\text {initial }}=0.45$ to $\eta_{\text {fracture }}=0.76$ due to localized necking [43]. Consequently, the accumulation of damage occurs in this range of stress triaxiality, where the shear damage term becomes progressively inactive.

\subsubsection{Comparison between the model predictions and experimental results}

All tests are simulated using the shear modified Gurson model to evaluate its predictive capabilities. The identified parameters are summarized in Table 5. Fig. 19 shows the force-displacement curves for notched tensile tests and shear tests. The experimental curves and numerically simulated curves are in good agreement for all tests in terms of the fracture displacement with a difference less than 1.5\%. Fig. 20 summarizes the displacement at fracture, predicted for the five tests, compared to the experimental results.

Remark: It is important to note that the results presented in this article were obtained after identification of the model parameters using a series for experimental tests, of our choosing. It should be noted that the choice of different tests could result in different parameters values for the modified Gurson model. That is, the results may become unstable or non-unique. It was emphasized in the work of Mahnken and Stein [44] that there are two possible reasons for the phenomenon of instability or non-uniqueness of the values of the model parameters:

(1) A deficiency in the model due to, for example, a high degree of linearity in its mathematical formulation that may not reflect the reality.

(2) A deficiency in the experiment data used to identify the model parameters. That is, not all the physical mechanisms which the model is intended to take into account are correctly activated during the tests.

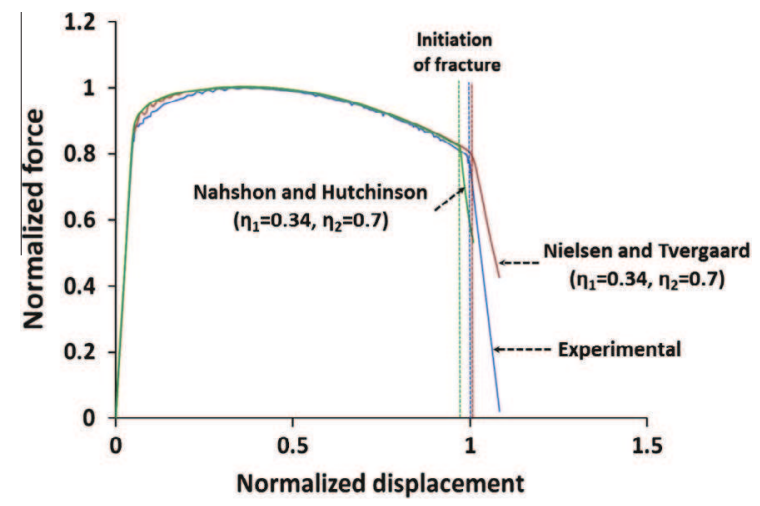

Fig. 18. Influence of the weight coefficients $\eta_{1}$ and $\eta_{2}$ on the prediction of the displacement at fracture for notched tensile specimens $(R=20 \mathrm{~mm})$. 
Table 5

Parameters of the shear modified Gurson model.

\begin{tabular}{llllllllll}
\hline Parameters & $f_{0}$ & $q_{1}$ & $q_{2}$ & $S_{N}$ & $f_{N}$ & $\varepsilon_{N}$ & $f_{\mathrm{c}}$ & $f_{f}$ & $k_{w}$ \\
\hline Values & 0.0015 & 1.2 & 0.8 & 0.1 & 0.02 & 0.2 & 0.08 & 0.13 & 0.86 \\
\hline
\end{tabular}

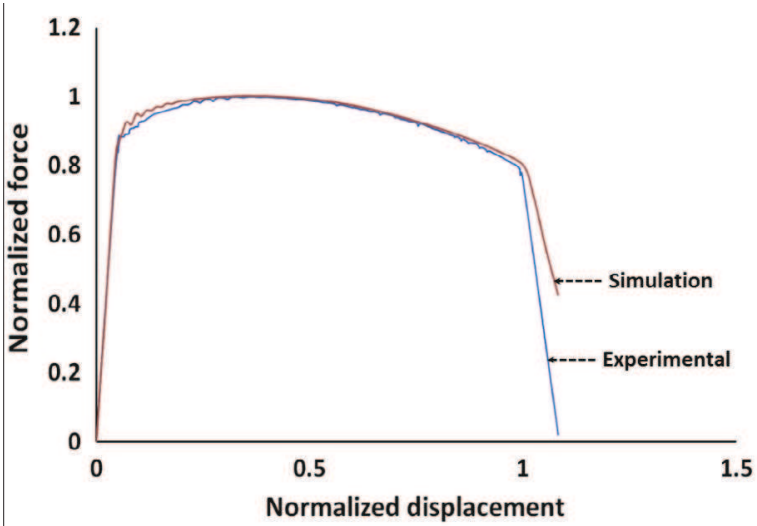

(a)

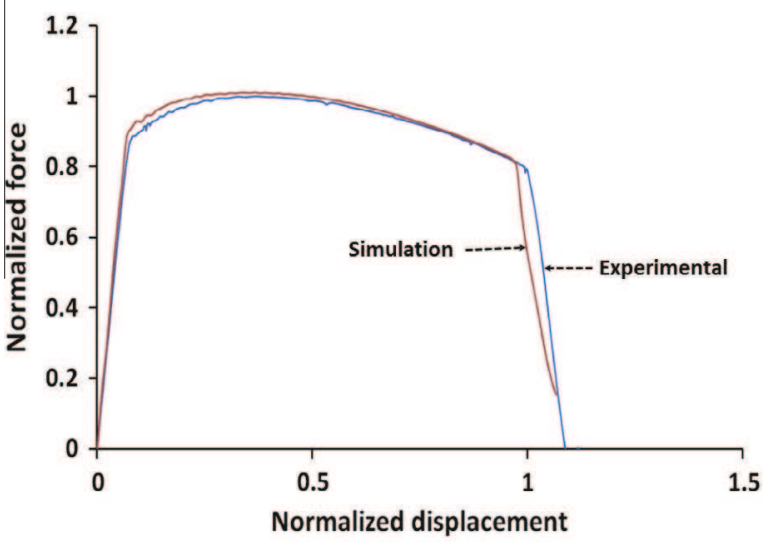

(c)

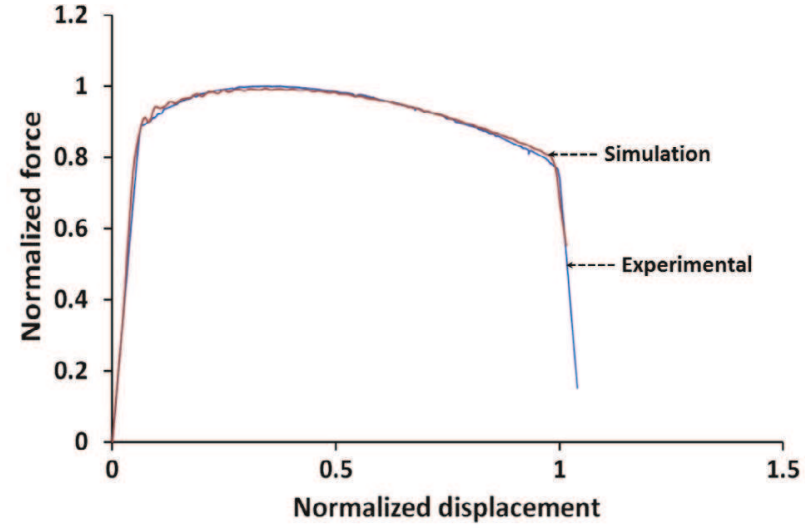

(b)

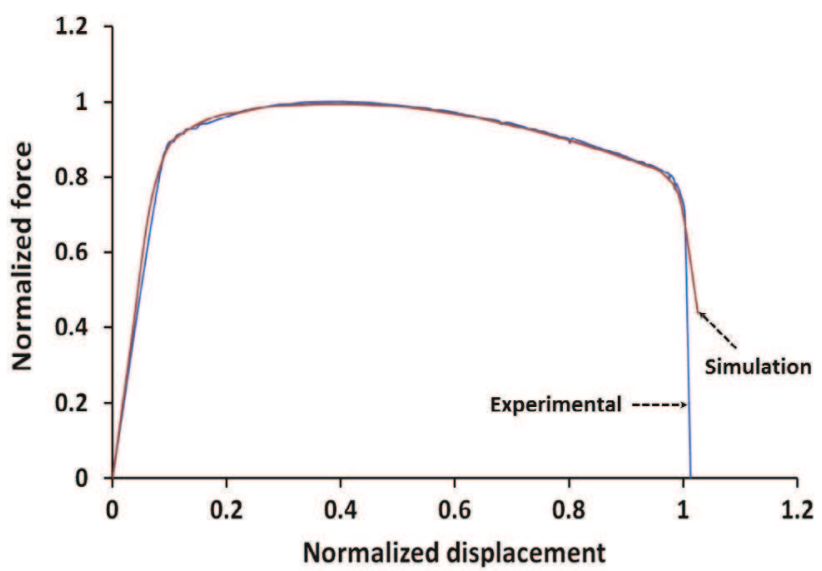

(d)

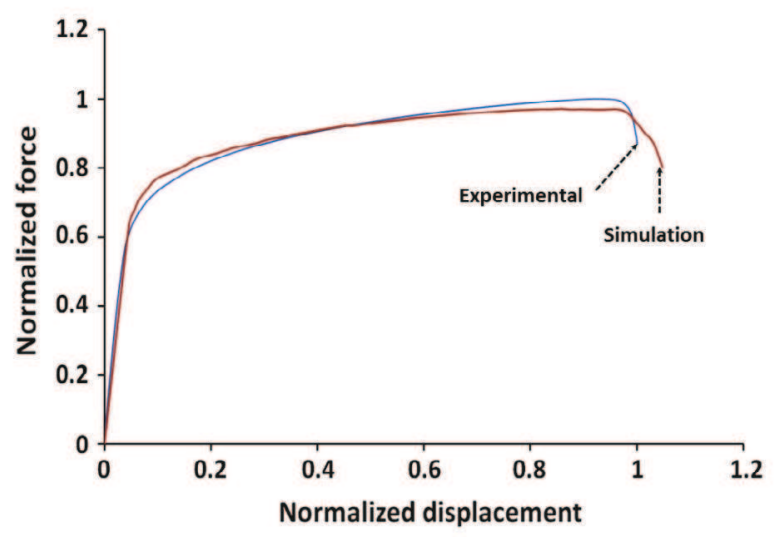

(e)

Fig. 19. Comparison between the experimental force-displacement curves and the predictions obtained by FE simulations using the modified Gurson model for: (a) notched specimens $(R=20 \mathrm{~mm})$, (b) notched specimens $(R=10 \mathrm{~mm})$, (c) notched specimens $(R=5 \mathrm{~mm})$, (d) notched specimens $(R=2 \mathrm{~mm})$ and $(\mathrm{e})$ shear specimens. 


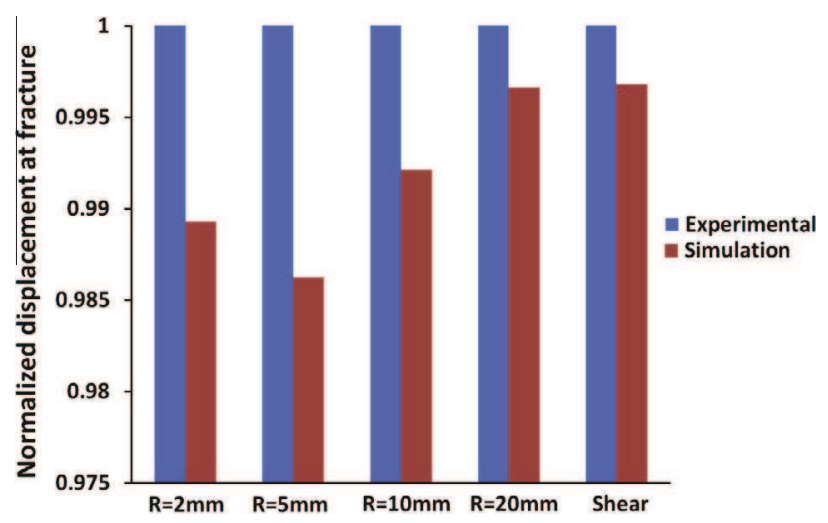

Fig. 20. Comparison between the predicted and experimental values of the normalized displacement at fracture.

However, due to the diversity of the test conditions selected in this work (i.e. they cover a wide range of stress states), it is expected that the results presented in the article give an accurate assessment of the performance of the model.

Future work should involve a more detailed study, by combining this macroscopic identification approach with quantitative microscopic investigation techniques, such as tomography, in order to better take into account the physical aspect of certain parameters and thus lead to a more stable solution.

\section{Application: punching process}

In order to validate the numerical modeling approach presented in the previous section, a series of experimental punching tests are carried out and compared with the numerical results.

\subsection{Experimental procedure}

Punching tests were carried out using a tool assembly mounted on a hydraulic press (type MIB with capacity of 100 tons), equipped with force and displacement sensors. The assembly consists of a punch and a die with circular shapes (Fig. 21). Two punches with two different diameters $D_{p}$ were used in order to vary the clearance between the punch and the die. The standard clearance is calculated as a percentage of sheet thickness by the following expression:

$J(\%)=\frac{D_{d}-D_{p}}{2 t} 100$

with $D_{p}$ is the punch diameter and $D_{d}$ is the die diameter. $(J=7 \%$ and $13 \%$ of the thickness of the sheet).

The radii of the cutting edges of the punch and the die are equal to $0.01 \mathrm{~mm}$. A load cell of type FGS (Fine Guidance Sensor, reference: FN-2554) with a maximum capacity of 50 tons is attached to the block punch to directly measure the applied force. The punch displacement is measured by a position sensor (BALLUFF 02F9-BTL). Both sensors are connected to the data acquisition system used to record data during the tests. The punching speed (which defines the cutting speed) is $300 \mathrm{~mm} / \mathrm{min}$.

\subsection{Finite element simulations}

The ABAQUS/Explicit finite element software has been used to simulate the punching process in $2 \mathrm{D}$ using the assumption of axisymmetry. The simulation conditions and initial finite element mesh are shown in Fig. 22. The elements in the shear zone have a size of $100 \times 100 \mu \mathrm{m}$. Four-node axisymmetric brick elements with reduced integration (CAX4R in ABAQUS/Explicit) are used. The Coulomb friction model is used to model the contact between the sheet and tools with a friction coefficient of 0.1. The punch and the die are considered to be rigid bodies. The ALE mesh option (Arbitrary Lagrangian Euleurian) [29] is activated so as to avoid element distortion. Two ductile fracture models are investigated to test their predictive capacity for the punching process:

- The classical GTN model.

- The GTN model modified for shear loads (studied in this work).

\subsection{Prediction of load/penetration curves}

Fig. 23 shows a comparison between the experimental and numerical load/displacement curves. Numerical curves for both

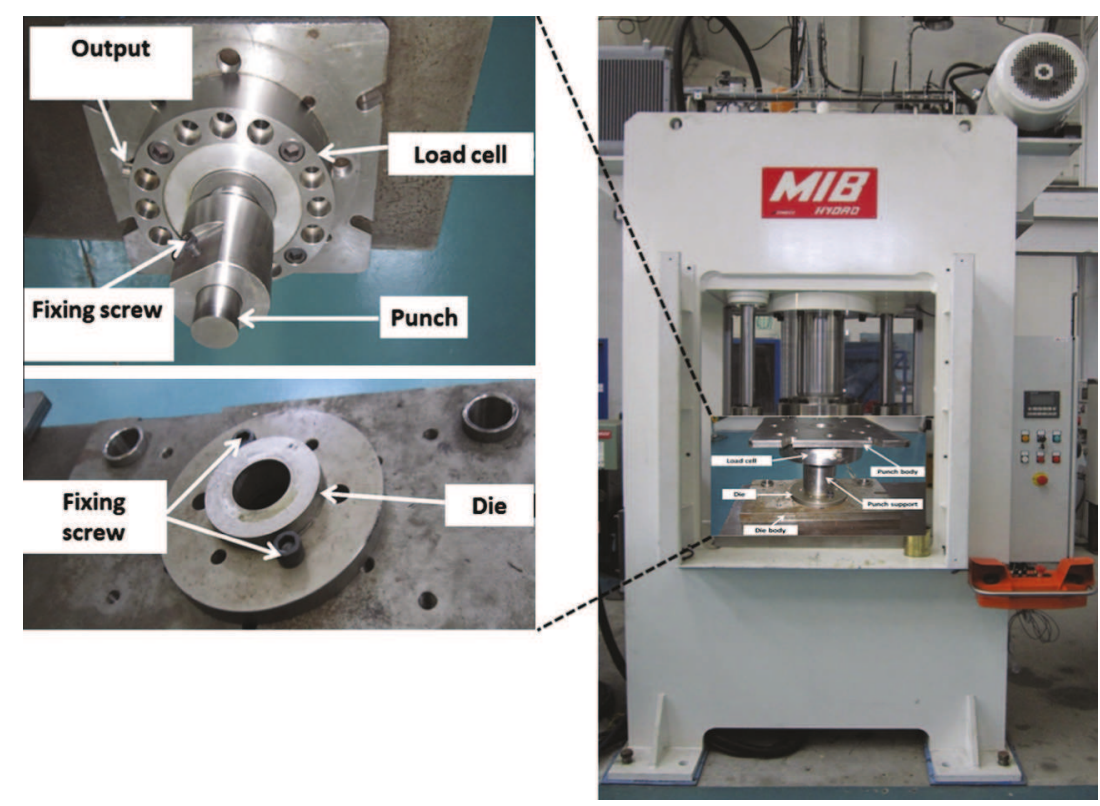

Fig. 21. Punching tools 


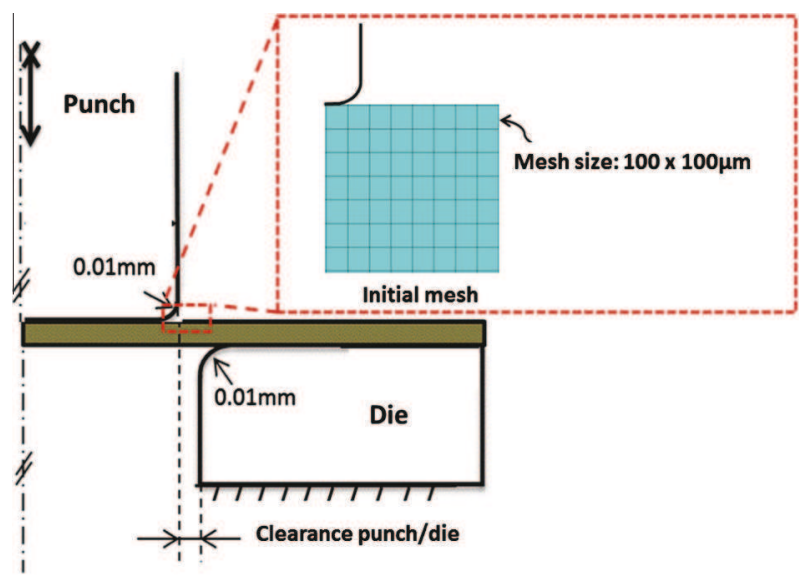

Fig. 22. Geometrical conditions of the punching process with the axisymmetric mesh.

the classical GTN model and the modified GTN model are shown. The numerical curves have a similar shape to the experimental curves for both clearances. It is observed that the modified GTN model provides better predictions for the maximum punching load, compared to the classic GTN model, for both clearances.

In the following, $U_{r}$ is defined as the punch penetration associated with the fracture initiation corresponding to the drop in the load/displacement curves. It can be observe that the modified GTN model gives good predictions for the penetration at fracture initiation $U_{r}$, when compared to the classic GTN model, for both

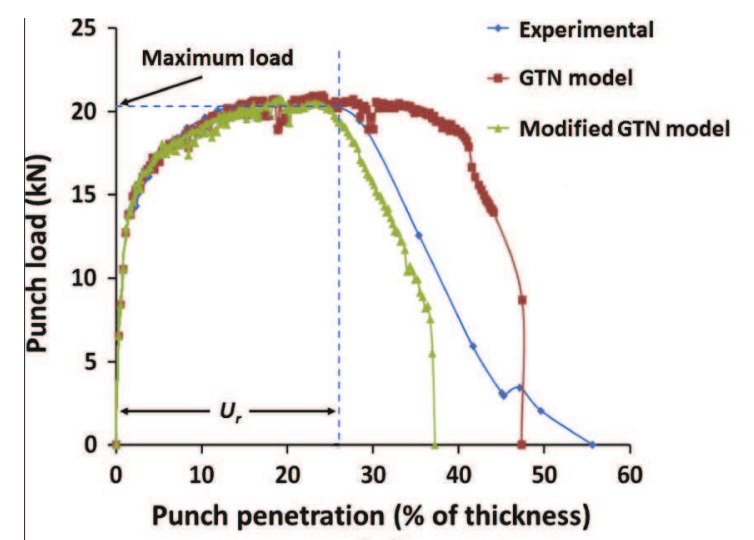

(a)

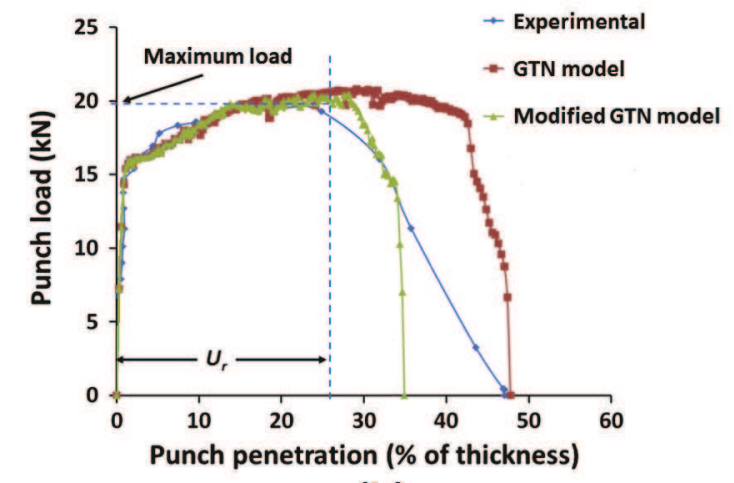

(b)

Fig. 23. Prediction of load/penetration curves: (a) $J=7 \%$ and (b) $J=13 \%$. clearances. Table 100 summarizes the prediction errors for the penetration at fracture initiation.

\section{Conclusion}

The present study has been organized in two distinct parts:

(1) The first was an experimental study concerning the damage behavior of the material for different stress states. From this work, the following conclusions can be made:

- The stress state influences the evolution of the damage mechanisms. For the case of shear dominated rupture, which is associated with low levels of stress triaxiality, the damage mechanisms can be described by a void nucleation phase, based on the fragmentation and/or debonding of the inclusions in the matrix. This is followed by elongation of the cavities and rotation in the shearing directions before the onset of coalescence. The micro-movement of the cavities observed in this study has been neglected in most work concerning the modeling of ductile fracture due to shear.

- The stress state also influences the macroscopic behavior of the material and the morphology of the fracture surface.

(2) The second part of the article was dedicated to the finite element modeling of the damage phenomenon. This work was focused on:

- The use of a Gurson type damage model, recently proposed to improve fracture predictions under conditions of both low and high stress triaxiality. This new approach is able of predicting shear softening via a parameter describing the magnitude of damage accumulation $k_{w}$.

- An identification strategy to determine the model parameters has been proposed, which is based on an experimental campaign that covers a wide range of stress states (both in terms of stress triaxiality and the third stress invariant). The use of these parameters in FE models result in good agreement with the experimental results in terms of predicting rupture, for the material investigated.

\section{References}

[1] Rousselier G. Ductile fracture models and their potential in local approach of fracture. Nucl Eng Des 1987;105:97-111.

[2] Besson J, Steglich D, Brocks W. Modeling of crack growth in round bars and plane strain specimens. Int J Solids Struct 2001;38:8259-84.

[3] Lemaitre J. A continuous damage mechanics model for ductile fracture. J Eng Mater Technol 1985;107:83-9.

[4] Chaboche J. Anisotropic creep damage in the framework of continuum damage mechanics. Nucl Eng Des 1984;79:309-19.

[5] Tvergaard V, Needleman A. Analysis of the cup-cone fracture in a round tensile bar. Acta Metall Mater 1984;32:157-69.

[6] Andrade Pires F, César de Sá J, Costa Sousa L. Numerical modelling of ductile plastic damage in bulk metal forming. Int J Mech Sci 2003;45:273-94.

[7] Chaboche J, Boudifa M, Saanouni K. A CDM approach of ductile damage with plastic compressibility. Int J Fract 2006;137:51-75.

[8] Rice J, Tracey D. On the ductile enlargement of voids in triaxial stress fields. J Mech Phys Solids 1969;17:201-17.

[9] Cockroft M, Latham D. Ductility and workability of metals. J Inst Met 1968;96:33-9.

[10] Tai W, Yang B. A new damage mechanics criterion for ductile fracture. Eng Fract Mech 1987;27:371-8.

[11] Stoughton T, Yoon J. A new approach for failure criterion for sheet metals. Int J Plast 2011;27:440-59.

[12] Kim J, Gao X, Srivatsan T. Modeling of crack growth in ductile solids: a threedimensional analysis. Int J Solids Struct 2003;40:7357-74.

[13] Kim J, Gao X, Srivatsan T. Modeling of void growth in ductile solids: effects of stress triaxiality and initial porosity. Eng Fract Mech 2004;71:379-400.

[14] Kim J, Zhang G, Gao X. Modeling of ductile fracture: application of the mechanism-based concepts. Int J Solids Struct 2007;44:1844-62. 
[15] Bao Y, Wierzbicki T. On fracture locus in the equivalent strain and stress triaxiality space. Int J Mech Sci 2004:81:81-98.

[16] Gao X, Wang T, Kim J. On ductile fracture initiation toughness: effects of void volume fraction, void shape and void distribution. Int J Solids Struct 2005; 42:5097-117

[17] Gao X, Zhang G, Roe C. A study on the effect of the stress state on ductile fracture. Int J Damage Mech 2009;19:75-94.

[18] Gao X, Kim J. Modeling of ductile fracture: significance of void coalescence. Int J Solids Struct 2006;43:6277-93.

[19] Barsoum I, Faleskog J. Rupture in combined tension and shear: experiments. Int J Solids Struct 2007;44:1768-86.

[20] Barsoum I, Faleskog J. Rupture in combined tension and shear: micromechanics. Int J Solids Struct 2007;44:5481-98

[21] Bai Y, Wierzbicki T. A new model of metal plasticity and fracture with pressure and Lode dependence. Int J Plast 2008;24:1071-96.

[22] Gurson AL. Continuum theory of ductile rupture by void nucleation and growth: part I - yield criteria and flow rules for porous ductile media. J Eng Matl Tech, Trans ASME 1977;9:2-15.

[23] Mirone G, Corallo D. A local viewpoint for evaluating the influence of stress triaxiality and Lode angle on ductile failure and hardening. Int J Plast 2010;26:348-71.

[24] Gao X, Zhang T, Zhou J, Graham S, Hayden M, Roe C. On stress-state dependent plasticity modeling: significance of the hydrostatic stress, the third invariant of stress deviator and the non-associated flow rule. Int J Plast 2011;27:217-31.

[25] Nahshon K, Hutchinson J. Modification of the Gurson model for shear failure. Eur J Mech A/Solids 2008;27:1-17.

[26] Nielsen K, Tvergaard V. Ductile shear failure or plug failure of spot welds modelled by modified Gurson model. Eng Fract Mech 2010;77:1031-47.

[27] Rakin M, Cvijovic Z, Grabulov V, Putic S, Sedmak A. Prediction of ductile fracture initiation using micromechanical analysis. Eng Fract Mech 2004;71:813-27.

[28] Agarwal H, Gokhale A, Graham S, Horstemeyer M. Void growth in 6061aluminum alloy under triaxial stress state. Mater Sci Eng 2003;34:35-42.

[29] Hibbitt, Karlsson, Sorensen. ABAQUS user's manual. Version 6.10, 2010.

[30] Chu C, Needleman A. Void nucleation effects in biaxially stretched sheets. J Eng Mater Technol 1980;102(3):249-56.
[31] Achouri M, Germain G, Dal Santo P, Saidane D. Numerical integration of an advanced Gurson model for shear loading: application to the blanking process. Comp Mater Sci 2013, in press.

[32] Malcher L, Andrade Pires F, César de Sá J. An assessment of isotropic constitutive models for ductile fracture under high and low stress triaxiality. Int J Plast 2012;30-31:81-115.

[33] Rakin M, Gubeljak N, Dobrojevic M, Sedmak A. Modelling of ductile fracture initiation in strength mismatched welded joint. Eng Fract Mech 2008;75:3499-510

[34] Prahl U, Bourgeois S, Pandorf T, Aboutayeb M. Damage parameter identification by a periodic homogenization approach. Comput Mater Sci 2002;25:159-65.

[35] Steglich D, Wafai H, Besson J. Interaction between anisotropic plastic deformation and damage evolution in Al 2198 sheet metal. Eng Fract Mech 2010;77:3501-18.

[36] Tvergaard V. Influence of voids on shear band instabilities under plane strain conditions. Int J Fract 1981;17:389-407.

[37] Tvergaard V. On localization in ductile materials containing spherical voids. Int J Fract 1982;18:237-52.

[38] Koplik J, Needleman A. Void growth and coalescence in porous plastic solids. Int J Solids Struct 1988;24:835-53.

[39] Brocks W, Sun D, Honig A. Verification of the transferability of micromechanical parameters by cell model calculation with visco-plastic materials. Int J Plast 1995;11:971-89.

[40] Faleskog J, Gao X, Shih C. Cell model for nonlinear fracture analysis I. Micromechanics calibration. Int J Fract 1998;89(4):355-73.

[41] Dunand M. Mohr D. On the predictive capabilities of the shear modified Gurson and the modified Mohr-Coulomb fracture models over a wide range of stress triaxialities and Lode angles. J Mech Phys Solids 2011;59:1374-94.

[42] Chhibber R, Singh H, Arora N, Dutta B. Micromechanical modelling of reactor pressure vessel steel. Mater Des 2012;36:258-74.

[43] Dunand M, Mohr D. Hybrid experimental-numerical analysis of basic ductile fracture experiments for sheet metals. Int J Solids Struct 2010;47(9):1130-43.

[44] Mahnken R, Stein E. Parameter identification of viscoplastic models based on analytical deri-vatives of a least-squares functional and stability investigations. Int J Plast 1996;12(4):451-79. 